\title{
Ichneumonid wasps from Madagascar. VI. The genus Pristomerus (Hymenoptera: Ichneumonidae: Cremastinae)
}

\author{
Pascal ROUSSE ${ }^{1}$, Claire VILLEMANT ${ }^{2} \&$ André SEYRIG $^{\dagger}$ \\ ${ }^{1}$ Iziko South African Museum, Natural History Department, PO Box 61, Cape Town 8000, South \\ Africa; Stellenbosch University, Department of Botany and Zoology, Evolutionary Genomics Group, \\ Private Bag X1, Stellenbosch 7602, South Africa \\ E-mail: rousse.pascal@wanadoo.fr (corresponding author) \\ ${ }^{2}$ Muséum National d'Histoire Naturelle, Dépt. Systématique \& Evolution, UMR7205 MNHN-CNRS, \\ CP50, 45 rue Buffon, 75005 Paris, France \\ E-mail: villeman@mnhn.fr \\ ${ }^{\dagger}$ Deceased author \\ ${ }^{1}$ urn:1sid:zoobank.org:author:B06C2640-700A-429B-AA2F-1BE09251C845 \\ 2 urn:1sid:zoobank.org:author:E93C2DD0-5DA8-43F6-9A53-07FE1F557B1A \\ $\dagger$ urn:lsid:zoobank.org:author:BE2CD298-C020-4860-8E27-772812C56DBE
}

\begin{abstract}
Pristomerus species of Madagascar are revised. We report 15 species, of which 12 are newly described: $P$. guinness sp. nov., $P$. hansoni sp. nov., $P$. kelikely sp. nov., $P$. keyka sp. nov., $P$. moramora sp. nov., P. melissa sp. nov., $P$. patator sp. nov., $P$. ranomafana sp. nov., $P$. roberti sp. nov., $P$. vahaza $\mathrm{sp}$. nov., $P$. veloma sp. nov. and $P$. yago sp. nov. Pristomerus albescens (Morley) and P. cunctator Tosquinet are newly recorded from Madagascar and new host and/or distribution records are provided for this species. A dichotomous key to all species is provided. The zoogeographical relation of the Malagasy fauna of Pristomerus with respect to mainland Africa is discussed: only three of the 15 species are reported to occur outside of Madagascar, suggesting a high level of endemism in Madagascar which was not unexpected.
\end{abstract}

Keywords. Parasitic wasps, Indian Ocean, biodiversity hotspot, taxonomy, description.

Rousse P., Villemant C. \& Seyrig A. 2013. Ichneumonid wasps from Madagascar. VI. The genus Pristomerus (Hymenoptera: Ichneumonidae: Cremastinae). European Journal of Taxonomy 49: 1-38. http://dx.doi.org/10.5852/ ejt.2013.49

\section{Introduction}

Madagascar and the nearby islands of the Western Indian Ocean have been classified as a "Biodiversity hotspot" (Myers et al. 2000). Its endemism rate is exceptionally high (Goodman \& Benstead 2003) and it remains one of the least investigated biogeographic areas on the planet. It is unfortunately also characterized by a rapid loss of natural habitats, mainly due to large-scale deforestation. The inventory of Malagasy biodiversity is therefore a priority for conservation purposes. André Seyrig (1897-1945) was a pioneer by collecting and inventorying the local entomofauna. He mainly focused on the huge 
family of Ichneumonidae. This family is expected to exceed 100,000 species (Gauld 1991), of which only 25,000 have been described (Yu et al. 2012).

André Seyrig was murdered before completing his tremendous task, and a large part of his work was left unpublished. His collections and manuscripts are kept at the Muséum National d'Histoire Naturelle, Paris (MNHN). Given the large interest of their content, we started to complete Seyrig's work by publishing a revision of Cremastinae of Madagascar (Rousse, Villemant \& Seyrig 2011). This large revision was, however, unfinished, since we could not include the genus Pristomerus Curtis, 1836. We thus complete here the full overview of the subfamily. Pristomerus are parasitoids of small Lepidoptera. They are firstly characterized (like some South American Xiphosomella) by the presence of thyridiae on the second metasomal tergite and of a tooth on the ventral edge of the hind femur, this latter character being, however, often absent or hardly visible in females. To date, only eight species of Pristomerus have been described from the entire Afrotropical region: our present revision shows that many are still to be described.

\section{Material and Methods}

\section{Material examined}

Seyrig collected specimens throughout Madagascar from 1921 to 1944. This material was re-identified to generic level using Townes's (1971) key, as well as unidentified specimens collected by Seyrig and others, including specimens collected from 2000 to 2003 during the "Terrestrial Arthropod Inventory of Madagascar", a project led by Brian Fisher and Charles Griswold (California Academy of Sciences). Seyrig (1932) and Heinrich (1938) found that less than $10 \%$ of the species of Pimplinae and Ichneumoninae known from Madagascar have a non-African origin. Despite high levels of endemicity, a Gondwanan origin of some ichneumonid groups in Madagascar was hypothesized to explain certain distribution patterns in the Southern Hemisphere (Gauld \& Wahl 2002). The specimens examined in this study were thus compared with the descriptions and holotypes of species reported in the Taxapad database of Ichneumonidae (Yu et al. 2012) that occur throughout Africa, the Indian subcontinent and among the Indian Ocean islands. Finally, the collections of the Iziko South African Museum were examined to check the potential distribution of the Malagasy species in mainland Africa.

\section{Abbreviations}

Fortunately, as several species were collected in large numbers by Seyrig, we were able to designate many paratypes and donate, as far as possible, one or two of them to the following institutions:

AMNH $=$ American Museum of Natural History, New York, USA
BMNH $=$ Natural History Museum, London, UK
CAS $=$ California Academy of Science, USA
ISAM $=$ Iziko South African Museum, Cape Town, South Africa
MNHU $=$ Museum für Naturkunde der Humboldt Universität, Berlin, Germany
MRAC $=$ Muséum Royal de l'Afrique Centrale, Tervueren, Belgium
IZPAN $=$ Instytut Zoologiczny Polska Adademia Nauk, Warsaw, Poland
NHRS $=$ Naturhistoriska Riksmuseet, Stockholm, Sweden

\section{Terminology and indices}

The morphological terminology and wing venation follows Wahl \& Sharkey (1993) and Gauld (1991), respectively (Fig. 1). The micro-sculpture was described following Fitton et al. (1988). With most of the examined insects being air dried for more than 70 years, the color indications should be considered with caution. The typology of the propodeal area basalis and the density of punctation follow Rousse et al. (2011). 
The measurements used in the study are as follows:

L: fore wing maximal length $(\mathrm{mm})$. These are successively given as the holotype length, and the length mean and range calculated on an indicated number of individuals (indicated in brackets, maximum 10).

CT: Clypeal transversality index $=\frac{\text { maximal width of clypeus }}{\text { central height of clypeus }}$

OOL: Oculo-Ocellar Line index $=\frac{\text { shortest distance between eye and lateral ocellus }}{\text { greatest diameter of median ocellus }}$

POL: Posterior Ocellar Line index $=\frac{\text { shortest distance between lateral ocelli }}{\text { greatest diameter of median ocellus }}$

ML: Malar Line index $=\frac{\text { shortest distance between eye and mandible }}{\text { basal width of mandible }}$

OT: Ovipositor sheath-hind Tibia index $=\frac{\text { length of ovipositor sheath }}{\text { length of hind tibia }}$

FFT: Female Femoral Tooth index estimates stoutness of the tooth on ventral face of femur for females (Fig. 2).

\section{Results}

The present study recognizes 15 Pristomerus Curtis, 1836(Arthropoda:Hexapoda: Insecta: Hymenoptera: Ichneumonidae: Cremastinae) species in Madagascar, 12 of which are considered as new:

P. albescens (Morley, 1917)

P. caris Fitton, 1994

P. cunctator Tosquinet, 1896

$P$. guinness sp. nov.

$P$. hansoni sp. nov.

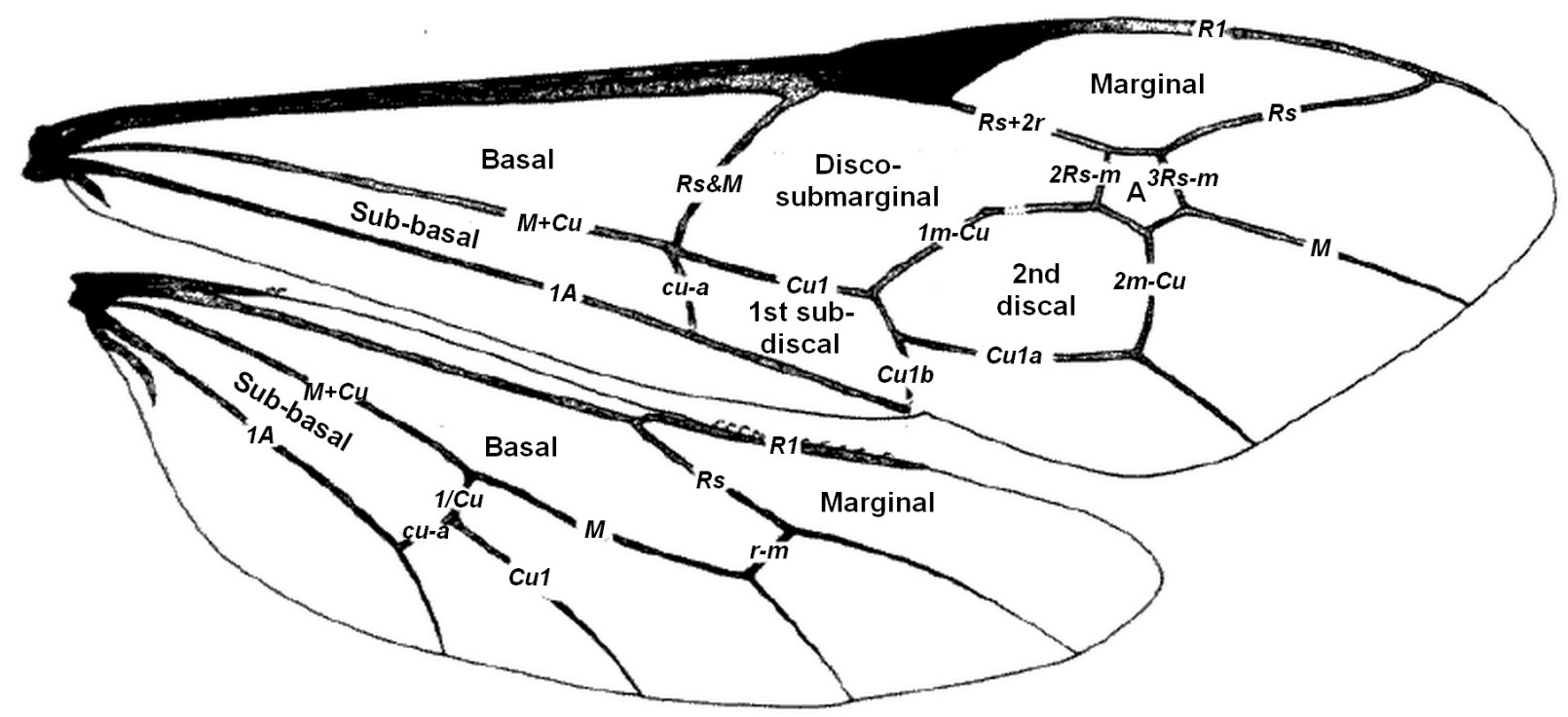

Fig. 1. Wing venation nomenclature (Gauld 1991). 
P. kelikely sp. nov.

P. kekya sp. nov.

P. melissa sp. nov.

P. moramora sp. nov.

P. patator sp. nov.

P. ranomafana sp. nov.

P. roberti sp. nov.

P. vahaza sp. nov.

P. veloma sp. nov.

P. yago sp. nov.

The key provided allows for the identification of these species. The reader may also refer to Table 1 , though correct identification of isolated male specimens of this genus may be not achievable. The species are presented in alphabetical order and new taxa are described. The examined specimens were collected by A. Seyrig unless otherwise stated. Except for $P$. keyka sp. nov. and P. ranomafana sp. nov. (deposited in the CAS collection), all holotypes are housed in the MNHN collection.

\section{Taxonomic descriptions}

Phylum Arthropoda Latreille, 1829

Class Insecta Linnaeus, 1758

Order Hymenoptera Linnaeus, 1758

Family Ichneumonidae Latreille, 1802

Subfamily Cremastinae Förster, 1869

Genus Pristomerus Curtis, 1836 (definition after Townes 1971)

\section{Diagnosis}

Body moderately slender, metasoma moderately to strongly compressed. Occipital carina usually complete. Females (often) and males (nearly always) with hind femur swollen and bearing a tooth on lower side. Forewing with areolet open (3rs-m absent), vein Rs\&M opposite or a little basal to vein $\mathrm{cu}-\mathrm{a}$, and $2 \mathrm{rs}-\mathrm{m}$ basal to $2 \mathrm{~m}-\mathrm{cu}$ by at least $2 \mathrm{rs}-\mathrm{m}$ length. Hindwing with vein $\mathrm{Cu} 1$ spectral. Tergite 1 moderately slender, glymma hardly distinct. Lower edges of tergite 1 separated and parallel. Epipleura of tergite 2 narrow, separated by a crease and turned under. Thyridium present, transverse or subcircular, located in basal 0.2 of tergite 2. Ovipositor tip most often sinuate. Apex of male gonosquama rounded.
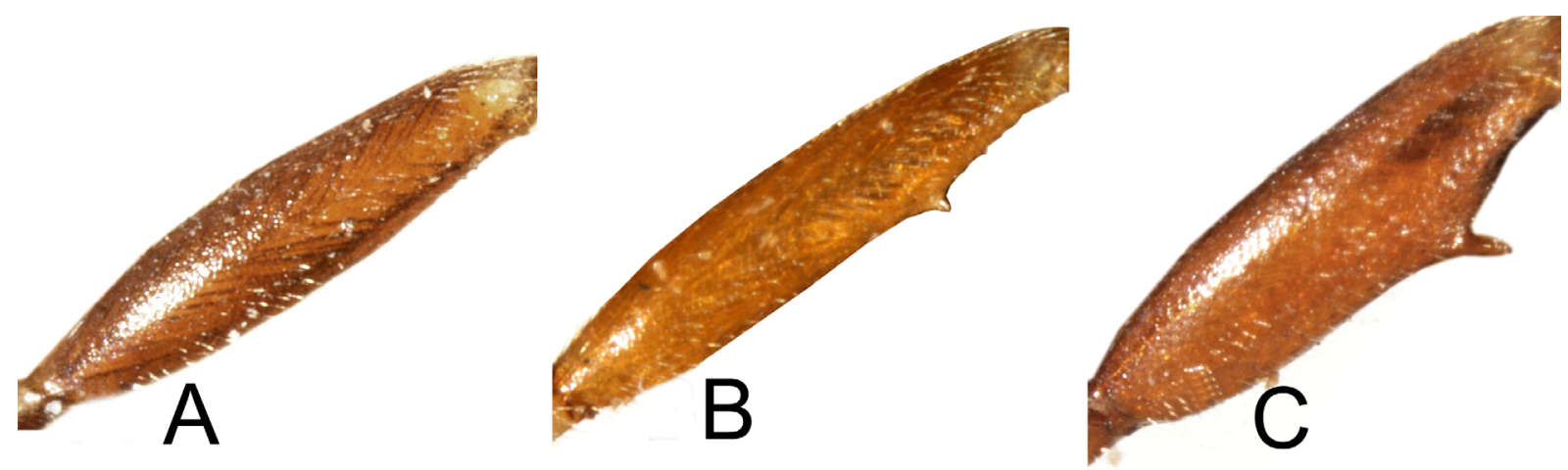

Fig. 2. Female Femoral Tooth index. A. Tooth absent $(\mathrm{FFT}=0)$. B. Tooth distinct, but wider than high $(\mathrm{FFT}=1)$. C. Tooth higher than wide $(\mathrm{FFT}=2)$. 
Table 1. Synoptic table for Pristomerus species of Madagascar. - Face (ground color). 0: yellowish to orage; 1: withish; 2: black brown. - Female. Wing (length), 0: $<3.6 ; 1$ : $3.6-5.5 ; 2$ : $>$ 5.5. Flag (number of flagellomeres), 0: $<25 ; \mathbf{1}: 25-33 ; \mathbf{2}$ : $>33$. OOL (oculo-ocellar index), 0: $<1 ; \mathbf{1}: 1.0-1.1$; $\mathbf{2}>1.1$. ML (Malar index), $\mathbf{0}: \leq 0.5 ; \mathbf{1}: 0.6-0.7 ; \mathbf{2}:>0.8$. CL (clypeal index), $\mathbf{0}:<1.7 ; \mathbf{1}: 1.8-2 ; \mathbf{2}>2$. Meso (mesosoma), $\mathbf{0}:<1.8 \mathrm{x} ; \mathbf{1}: 1.8-2 \mathrm{x} ; \mathbf{2}:>2 \mathrm{x}$ as long as wide. ASM (area superomedia), $\mathbf{0}$ : lateral carinae lacking; $\mathbf{1}<2.5 \mathrm{x}, \mathbf{1}: \geq 2.5 \mathrm{x}$ as long as wide. FFT (Female femoral tooth index), see Fig. 2. OT (Ovipositor-hind tibia index), 0: $<1.5 ; 1: 1.5-1.9 ; 2: 2.0-2.5 ; 3:>2.5$. - Male. OO (oculo-ocellar index), $\mathbf{0}:<0.4 ; \mathbf{1}: 0.4-0.8 ; 2:>0.8$.

\begin{tabular}{|c|c|c|c|c|c|c|c|c|c|c|c|}
\hline \multirow{2}{*}{ Species } & \multirow{2}{*}{ Face } & \multicolumn{9}{|c|}{ Female } & \multirow{2}{*}{$\begin{array}{r}\text { Male } \\
\text { OO }\end{array}$} \\
\hline & & Wing & Flag & OOL & ML & CL & Meso & ASM & FFT & OT & \\
\hline P. albescens & 0 & 0 & 1 & 1 & 0 & 0 & 0 & 1 & 1 & 0 & 2 \\
\hline P. caris & 1 & $0-1$ & 1 & 1 & 0 & 0 & 0 & 1 & 0 & $0-1$ & 0 \\
\hline P. cunctator & 0 & 1 & $1-2$ & 1 & 1 & 1 & 1 & 1 & 1 & $0-1$ & 0 \\
\hline P. guinness & 1 & $1-2$ & 2 & 0 & 1 & 1 & 1 & 2 & 1 & $0-1$ & 0 \\
\hline P. hansoni & 1 & 2 & 2 & 0 & 1 & 0 & 1 & 2 & 0 & 3 & 0 \\
\hline P. kelikely & 0 & $0-1$ & 1 & 2 & 1 & 1 & 1 & 1 & 0 & 1 & 2 \\
\hline P. keyka & 0 & 0 & 0 & 0 & 2 & 1 & 0 & 1 & 1 & 1 & NA \\
\hline P. melissa & 2 & 1 & 2 & 1 & 2 & 1 & 1 & 0 & 1 & 0 & NA \\
\hline P. moramora & 0 & 0 & 1 & 2 & 0 & 2 & 0 & 2 & 0 & 1 & 2 \\
\hline P. patator & 0 & 2 & 2 & 1 & 2 & 0 & 0 & 2 & 1 & 1 & 1 \\
\hline P. ranomafana & 1 & 1 & 1 & 2 & 1 & 1 & 1 & 1 & 0 & 2 & NA \\
\hline P. roberti & 0 & 1 & 1 & 2 & 0 & 2 & 1 & 1 & 1 & 2 & 0 \\
\hline P. vahaza & 1 & 1 & 1 & 1 & 0 & 0 & 2 & 2 & 0 & 0 & 1 \\
\hline P. veloma & 0 & 2 & 2 & 0 & 0 & 1 & 0 & 1 & 2 & 1 & 0 \\
\hline P. yago & 0 & 1 & $1-2$ & 1 & 0 & 0 & 0 & 1 & 2 & 1 & 0 \\
\hline
\end{tabular}

\section{Remarks}

Pristomerus is a large genus of 100 species worldwide (Yu et al. 2012). Most species are tropical. Hosts include various small Lepidoptera living in tunnels, leaf rolls, buds and other shelters. This genus is usually well differentiated from the New World genus Xiphosomella Szépligeti by the position of the thyridiae on tergite 2, which in Pristomerus are separated from the anterior margin by at most their own diameter, and most usually further back in Xiphosomella. Additionally, the forewing areolet is always open and the ovipositor tip nearly always sinuate in Pristomerus. As stated by Gauld (2000) this combination of features sometimes fails to unambiguously differentiate from Pristomerus some species in the extreme end of the variation range of Xiphosomella. Subsequently, both genera are susceptible to be eventually merged in absence of clearer autapomorphies. 


\section{Key to Pristomerus species of Madagascar}

1 Face and inner orbits dark brown, clypeus white (Fig. 10C); area superomedia hardly delimited laterally (male unknown) .P. melissa sp. nov.

- Face differently colored, white to orange, if medially dark then inner orbits strikingly paler; area superomedia almost always laterally delimited

2 Ground color of face white (e.g., Fig. 6C), sometimes with a more or less large dark midlongitudinal marking (e.g., Figs 4B, 13B)

- Ground color of face yellowish to orange (e.g., Figs 5B, 16B)

3 Metasomal tergites dark brown with wide white apical margin; female femoral tooth small but distinct $(\mathrm{FFT}=1)$; male with lateral ocellus nearly contiguous with eye $(\mathrm{OOL}=0.1)$

P. guinness sp. nov.

- Metasoma differently colored; female femoral tooth absent or hardly present as a weak angulation $(\mathrm{FFT}=0)$; male with lateral ocellus more distant from eye (OOL > 0.1) (male of P. ranomafana unknown)

4 Mesosoma elongate, more than $2 \mathrm{x}$ as long as wide; ovipositor relatively short $(\mathrm{OT}<1.5)$; male with lateral ocellus relatively far from eye $(\mathrm{OOL}=0.6) \ldots \ldots \ldots \ldots \ldots \ldots \ldots . . . . P$. vahaza sp. nov.

- Mesosoma at most $2 \mathrm{x}$ as long as high; ovipositor longer (OT $\geq 1.5$ ); male with lateral ocellus closer to eye $(\mathrm{OOL}=0.2)$ (male of $P$. ranomafana unknown)

5 Ovipositor very long (OT $>2.5)$, pterostigma orange P. hansoni sp. nov.

- Ovipositor shorter $(1.5<\mathrm{OT}<2.3)$, pterostigma brown

6 Forewing with $2 \mathrm{rs}-\mathrm{m}$ at least $0.5 \mathrm{x}$ as long as $2 \mathrm{~m}-\mathrm{cu}$; ovipositor moderately long (OT 1.5-1.8) .P. caris Fitton

- Forewing with $2 \mathrm{rs}-\mathrm{m}$ shorter, about $0.3 \mathrm{x}$ as long as $2 \mathrm{~m}-\mathrm{cu}$; ovipositor longer $(\mathrm{OT}>2)$ (male unknown) P. ranomafana sp. nov.

7 Female femoral tooth absent $(\mathrm{FFT}=0)$; male with ocelli hardly enlarged, distant from eyes $(\mathrm{OOL}=$

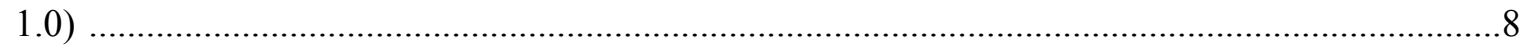

- Female femoral tooth present, though sometimes reduced to a small tubercle (FFT 1 or 2); male, where known, with ocelli enlarged and closer to eye $(\mathrm{OOL}<1)$ n.b. Males of $\mathrm{P}$. albescens could key here because their lateral ocelli are distinctly removed from eyes. They can however be distinguished by their transverse head with narrow clypeus $(C T=1.4)$.

8 Antenna with more than 30 flagellomeres; mesosoma about $2 \mathrm{x}$ as long as wide, body uniformly orange P. kelikely sp. nov.

- Antenna with fewer than 30 flagellomeres; mesosoma stouter, body with dark brown markings ..P. moramora sp. nov.

9 Face at least with yellow margins along inner orbits; female femoral tooth small $(\mathrm{FFT}=1) \ldots$

- Face rufo-testaceous; female femoral tooth stronger (FFT = 2)

10 Ovipositor relatively short (OT $<1.4)$, its tip straight; head transverse with clypeus narrow (CT $<1.5)$ ..P. albescens (Morley)

- Ovipositor longer (OT 1.5-2.5), apically sinuate; head not distinctly transverse, clypeus more transverse $(\mathrm{CT}>1.5)$. 
11 Antenna with fewer than 25 flagellomeres; mesoscutum granulate with sparse punctures along notaulus; small species $(\mathrm{L}<3.2)$ (male unknown) P. keyka sp. nov.

- Antenna with more than 25 flagellomeres; mesoscutum moderately to densely punctategranulate; larger species $(\mathrm{L}>3.5)$

12 Antenna with more than 36 flagellomeres; pterostigma orange; propodeum with area superomedia hardly defined laterally; large species $(\mathrm{L}=5.8)$ P. patator sp. nov.

- Antenna with fewer than 36 flagellomeres; pterostigma brown; propodeum with area superomedia complete; smaller species $(\mathrm{L}<5.5)$

13 Clypeus strongly transverse $(\mathrm{CT}>2.5)$; malar line short $(\mathrm{ML}=0.4)$, mesonotum orange ..P. roberti sp. nov.

- Clypeus narrower $(\mathrm{CT}<2)$, malar line longer $(\mathrm{ML}=0.7)$, notaulus and scutellum yellow ..P. cunctator Tosquinet

14 Mesonotum densely punctate; face not distinctly transverse; large species ( $\mathrm{L}>7.0)$

P. veloma sp. nov.

- Mesonotum almost smooth; head distinctly transverse with clypeus narrow $(\mathrm{CT}=1.5)$; smaller species $(\mathrm{L}<5.0)$ P. yago sp. nov.

\section{Pristomerus albescens (Morley, 1917)}

Fig. 3

Pristomeridia albescens Morley, 1917: 224.

\section{Diagnosis}

Small species; face pale yellow; head and mesosoma pale yellow with brown markings, metasoma dark brown, tergite 4 and following lighter, more or less yellow maculated; head strongly constricted behind eyes; face transverse and ventrally narrowed, densely punctate, clypeus smooth, narrow, convex in profile; mesoscutum densely punctate, scutellum moderately punctate with posterior face striate; area superomedia about $2 \times$ longer than wide; female femoral tooth small, sometimes reduced to a small angulation; ovipositor moderately short, its tip straight; POL 1.9; OOL 1.1; CT 1.4; ML 0.5; OT 1.3; FFT 1.

\section{Differential diagnosis}

Closely related to P. moramora, but readily distinguishable by the straight tip of ovipositor, the transverse head and the relatively narrow clypeus.

\section{Etymology}

Euphonic arrangement of letters.

\section{Material examined}

\section{Lectotype}

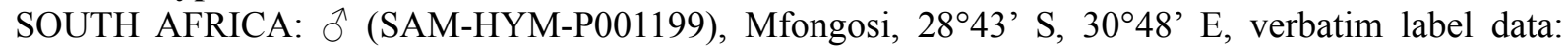
"Mfongosi, Zulu L., W.E. Jones, April 1926", metasoma, antennae and most of legs lacking.

\section{Paralectotype}

SOUTH AFRICA: + (SAM-HYM-P001223), same label data. 


\section{Other material examined}

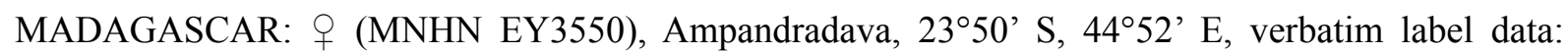

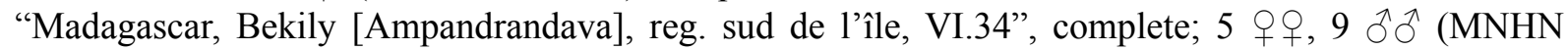
EY3551, EY8671-8683), same locality, Apr. 1934, May, Sep.-Nov. 1936, Jan., Mar. and May 1937,


1938, Jan. 1941; 1 ㅇ (MNHN 1 EY8696), Ankaratra, Feb. 1941; 8 우 Bekily, May, Sep.-Oct. 1936, Sep. 1938 (one to each of the above mentioned institutions). - TANZANIA: 6 + $q$ (ISAM), Mkomazi game reserve, Dec. 1995-Apr. 1996. - SOUTH AFRICA: 2 우으 (ISAM), Western Cape, Gamkaberg game reserve, Dec. 2008-Jan. 2009.

\section{Description}

\section{Female}

LeNGTH. 3.5, 3.4 (3.1-3.5) (10 specimens).

HeAd. Strongly constricted behind eyes. Temple short. Ocellar triangle anteriorly acute. Face distinctly narrowed ventrally. Frons and vertex granulate, face densely but superficially punctate. Clypeus rounded
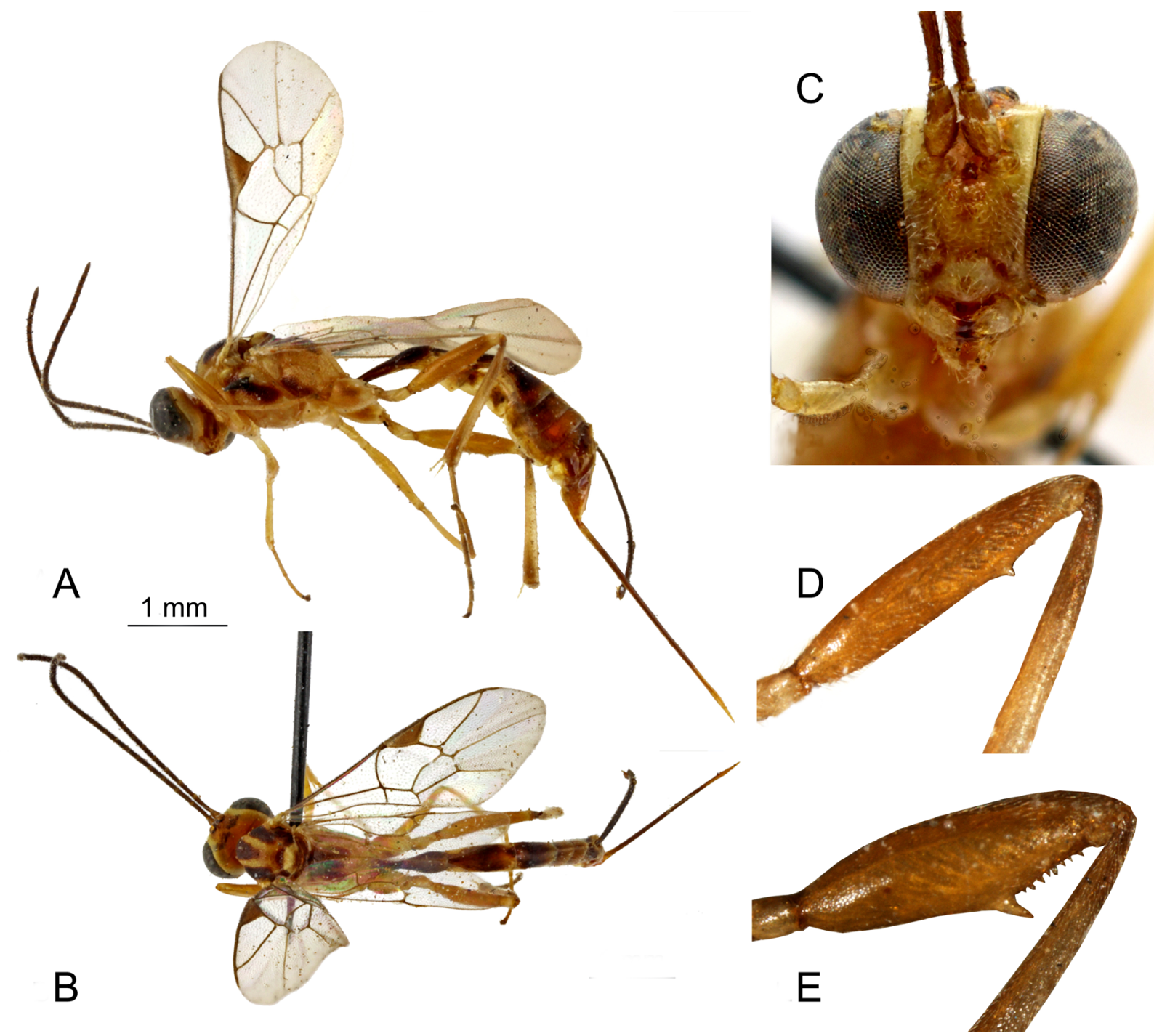



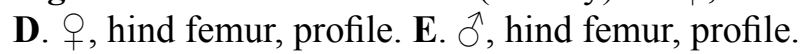


and convex, almost smooth. Mandible short and stout, teeth subequal. Malar line short. Antenna with 30-31 flagellomeres.

Mesosoma. Stout, about $1.6 \mathrm{x}$ longer than high. Pronotum almost smooth with few punctures centrally. Mesonotum matt, densely punctate-granulate, some punctures confluent. Scuto-scutellar groove longitudinally striate. Scutellum moderately punctate, shining, its vertical posterior margin longitudinally striate. Mesopleuron densely punctate and shining, metapleuron more granulate. Propodeum shining, moderately punctate, area petiolaris transversally wrinkled. Area basalis opposite (sometimes petiolate or truncate), area superomedia about 2 x longer than wide and slightly shorter than area petiolaris. Legs: femoral tooth distinct but small, sometimes only present as a weak protuberance.

Metasoma. Post-petiole, tergite 2 and base of tergite 3 finely aciculate. Tergite 2 slightly shorter than tergite 1 , about $2.5 \mathrm{x}$ longer than apically wide. Thyridia elongate-oval. Ovipositor moderately long, its tip straight.

Color. Antenna brown, scape and pedicel ventrally orange. Head and mesosoma yellow with dark maculae. Dark brown to brown: frons, vertex, lobes of mesonotum, a transverse spot on mesopleuron and metapleuron, scuto-scutellar groove, apex of scutellum and post-scutellum, metanotum and median basal half of propodeum (in some individuals, the dark marking is faded on pleurae, scutellum and propodeum). Legs yellow, front and mid coxae and all trochanters white, hind leg more orange with tarsus and tibia basally and apically infuscate; dorsal margin of hind tibia white. Wings hyaline, pterostigma light brown. Metasoma brown, tergites 1-3 dark brown, their apex more or less bordered with yellow, lateral margins of tergite 2 sometimes bordered with yellow, other tergites brown orange. Thyridia yellow. Ovipositor sheath brown.

\section{Male}

Length: 3.3. (3.1-3.4) (10 specimens). Posterior ocelli equally distant from each other as from eyes $(\mathrm{POL}=\mathrm{OOL}=0.9)$. Hind femur swollen, femoral tooth long and sharp, followed by a row of small denticles. Otherwise similar to female.

\section{Distribution}

Madagascar (Toliara province), Tanzania (new distribution records), South Africa.

\section{Remarks}

The straight ovipositor is a very rare feature in Pristomerus spp. mentioned by Townes (1971) in only one undescribed Afrotropical species.

Pristomerus caris Fitton, 1994

Fig. 4

\section{Diagnosis}

Moderately sized species; face ivory white, more or less dark maculated medially; head white and black, mesosoma and metasoma brownish orange with tergites 1-3 blackish brown, mesosoma sometimes with black spots dorsally; face sparsely punctate, clypeus smooth and transverse; mesoscutum densely punctate-granulate, scutellum finely and sparsely punctate; area superomedia 1.9-2.7 x longer than wide; female femoral tooth absent; ovipositor moderately long, apically sinuate; POL 0.7 ; OOL 1.1 ; CT 1.8; ML 0.5; OT 1.5-1.7; FFT 0. 


\section{Differential diagnosis}

Closely related to P. vahaza. Both share the same color pattern but may be distinguished by the shape of mesosoma, distinctly elongate in $P$. vahaza, and by the scutellum which is flat in $P$. vahaza and convex in P. caris.

\section{Material examined}

\section{Holotype}


"Madagascar: Lac Alaotra, Stn Cala, 12 Feb. 1988 (coll. P. Bousses)", complete.

Paratype

MADAGASCAR: $\widehat{\jmath}(\mathrm{BMNH})$, same locality, same date.

\section{Other material examined}

MADAGASCAR: 5 우 (MNHN), Mandreka forest, Dec. 1929 and Nov. 1936; 2 우 (MNHN), Antananarivo, Jan. 1930 and Dec. 1933 (coll Olsoufieff); 2 우 (MNHN), Lac Alotra, Aug. 1928; 1 ㅇ (MNHN), Antsirabe, Jan. 1940; 1 q (MNHN), Ambositra, Feb. 1934; 2 q 9 (MNHN), Andreba, Nov.



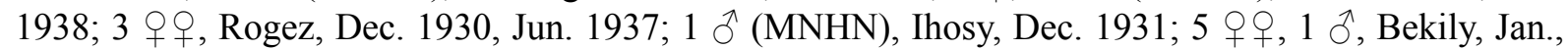
Mar.-Apr. 1933, Apr. 1934, Dec. 1936; 1 ठ (MNHN), Tsingjoarivo, Mar. 1932; 14 우, 1 ○े (MNHN), Ankaratra (1800 m), Mar. 1940, Feb., Mar. and May 1941; 1 ㅇ (CAS), verbatim label data: "Province Fianarantsoa, Parc Nat. Ranomafana, 14-21 January 2002, $21^{\circ} 15.05^{\prime}$ S, $47^{\circ} 24.43^{\prime}$ E (colls: M. Irwin, R. Harin'Hala, malaise, radio tower at forest edge in mixed tropical forest, elev. $1130 \mathrm{~m}, \mathrm{MA}-02-$ 09B-12)"; 1 ㅇ (CAS), verbatim label data: "Toamasina Province, botanic garden near entrance to Andasibe Nat. Park, $18^{\circ} 55.58^{\prime}$ S, 48 $8^{\circ} 24.47^{\prime}$ E, 7-16 November 2001 (colls: M. Irwin, R. Harin'Hala, malaise, in tropical forest, elev. 1025 m, MA-01-08B-19)"; 8 우, Rogez, Sep. and Dec. 1930, Nov. 1931, Feb. and Jun. 1932, May 1936 (one to each of the above mentioned institutions). Males with small

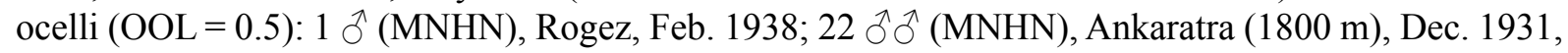
Feb. 1938 and 1941, Feb.-Mar. 1940.

\section{Description}

\section{Female}

Length. 4.1, 4.2 (3.3-4.7) (10 specimens).

HEAD. Temple short, head distinctly constricted behind eyes. Vertex finely granulate. Face shining, sparsely punctate. Clypeus smooth, shining, transverse. Malar line short. Mandible short and stout. Ocellar triangle acute. Antenna with 29-32 flagellomeres.

Mesosoma. Stout, 1.5-1.7 x longer than high. Pronotum smooth, shining, the antero-ventral part with an irregular surface, epomia raising dorsally. Mesonotum densely punctate-granulate, its apical $1 / 5$ smooth. Mesopleuron shining and densely punctate. Metapleuron punctate-granulate. Scuto-scutellar groove smooth, sometimes with weak longitudinal wrinkles. Scutellum slightly convex, smooth with sparse and fine punctures. Propodeum strongly carinated, moderately punctate and shining. Area basalis short, petiolate, opposite or truncate. Area superomedia long, 1.9-2.7 x longer than wide (usually about 2 ), area petiolaris wider and more or less wrinkled apically. Hind femur moderately slender, without femoral tooth. Fore wing with $2 \mathrm{rs}-\mathrm{m}$ basal to $2 \mathrm{~m}-\mathrm{cu}$ by $2 \mathrm{x}$ its length.

Metasoma. Tergites 1-3 finely aciculate. Thyridia oval to subcircular. Ovipositor moderately long.

COLOR. Brownish orange overall. Head ivory white. Blackish brown: antennae, center of frons, vertex and occiput. A pair of black spots generally extends from vertex through outer orbits. Face more or 
less mid-longitudinally infuscate. Darker specimens also bear black maculae on mesoscutum and propodeum. Tergites 1-3 black-brown with base of tergite 1 lighter (yellow to orange). Thyridia yellow. Hind tarsus infuscate. Ovipositor sheath blackish. Wings hyaline, pterostigma dark brown to testaceous.

\section{Male}

Length: 3.8 (3.5-4.2) (10 specimens). Face widened ventrally, ocelli enlarged and very close to eyes posteriorly $(\mathrm{OOL}=0.2)$ except for 22 males from Ankaratra and 1 from Rogez whose ocelli are smaller $(\mathrm{OOL}=0.5)$. Hind femur swollen, bearing an acute tooth followed by a row of denticles. Otherwise similar to female.

\section{Host records}

Maliarpha separatella Ragonot (Lepidoptera: Pyralidae) (Polaszek et al. 1994).

\section{Distribution}

Madagascar (widely distributed).

\section{Remarks}

The large series of specimens available in Seyrig's collection shows considerable variation with respect to the description of $P$. caris by Polaszek et al. (1994). The propodeum carination is highly variable, with



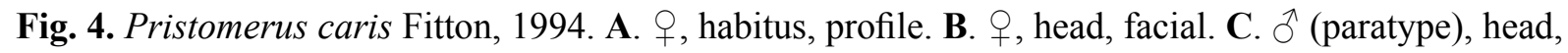
dorsal. D. $\hat{o}$ (Ankaratra), head, dorsal. E. + , mesosoma, dorsal. F. + , hind femur, profile. G. $\hat{o}$, hind femur, profile. 
area basalis petiolate to truncate, and area superomedia which greatly varies in length. Color also varies from lighter specimens with reduced brownish markings to darker ones with larger black spots on face, vertex, mesoscutum and propodeum. We furthermore observed two male groups with differently sized ocelli (Fig. 4C, D). Such variability is however not correlated with any other plastic or geographical difference. These specimens might represent a species complex whose study needs more comprehensive molecular and morphometric investigations.

Pristomerus cunctator Tosquinet, 1896

Fig. 5

\section{Diagnosis}

Rather large species; face yellow; head and mesosoma orange and yellow, metasoma orange with variable infuscate markings; face densely punctate, slightly widened ventrally, clypeus strongly transverse and smooth; mesoscutum densely punctate-granulate (almost smooth in male), scutellum moderately punctate; area superomedia about $2.5 \mathrm{x}$ longer than wide; female femoral tooth small; ovipositor moderately short, its apex sinuate; POL 1.0; OOL 1.0; CT 1.8; ML 0.7; OT 1.4-1.5; FFT 1.

\section{Differential diagnosis}

Species recognizable by the combination of the color pattern and the almost smooth mesoscutum of male.

\section{Material examined}

Lectotype

MOZAMBIQUE: + (MNHU 26283), verbatim label data: "Delagoa-Bai (Mozambique)", no collection date, complete.

\section{Other material examined}

MADAGASCAR: 13 우, 24 ठึ (MNHN), Bekily, Mar. 1930, Apr. 1930, April 1932, Mar.-May1933, Mar.-Jun. 1934, May-Jul., Sep., Oct. and Dec. 1936, Feb. 1937; 2 ठิ (MNHN), Betroka, Feb.-Mar.

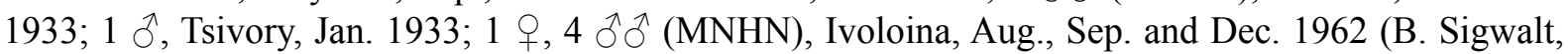
coll.); 8 우, 8 ô $\hat{O}^{\lambda}$ (MNHN), Bekily, Mar., Apr. and Oct. 1933, Jul. 1934 (two deposited in each of the institutions mentioned above).

\section{Description}

\section{Female}

LeNGTH. 5.4, 4.9 (4.2-5.4) (10 specimens).

HEAD. Strongly constricted behind eyes. Temple short. Face slightly widened ventrally. Vertex and lateral margin of frons granulate, face more densely punctate centrally than laterally. Clypeus transverse, almost smooth. Mandible with teeth subequal; malar line rather short. Antenna with 32-35 flagellomeres.

Mesosoma. Moderately elongate, nearly $2 \mathrm{x}$ longer than high. Pronotum shining, sparsely and superficially punctate anteriorly. Mesoscutum densely punctate-granulate, some punctures almost confluent. Scutoscutellar groove almost smooth. Scutellum shining, moderately punctate. Mesopleuron shining, densely punctate, speculum smooth. Metapleuron densely punctate-granulate. Propodeum shining, densely punctate laterally. Area basalis opposite or truncate, area superomedia about $2.5 \mathrm{x}$ longer than wide. Area petiolaris transversally wrinkled. Hind femur with a distinct small tooth.

Metasoma. Tergites 1-2 finely aciculate. Tergite 2 about $2 \mathrm{x}$ as long as apically wide. Thyridia rounded, separated from each other by about $4 \times$ their diameter. Ovipositor slightly up-curved, its apical $1 / 3$ sinuate. 
CoLoR. Body orange with yellow markings. Antenna brown, scape and pedicel orange. Head yellow with central part of frons, vertex and occiput orange. Mesosoma orange except yellow parts: anterior part of pronotum, notauli, lateral margin of mesoscutum, scutellum, tegula, subalar prominence, postero-ventral corner of mesopleuron, posterior part of metapleuron, and propodeum. Legs orange, apex of coxae and all trochanters yellow. Wings hyaline, pterostigma light brown. Mesosoma orange, the base of tergite 2 sometimes infuscate centrally.

\section{Male}

LENGTH: 5.3. (4.2-5.9) (10 specimens). Median lobe of mesoscutum moderately punctate-granulate anteriorly, remainder of mesonotum almost smooth. Face widened ventrally and distinctly larger than frons. Posterior ocellus close to eyes $(\mathrm{OOL}=0.3)$. Hind femur swollen, femoral tooth long and sharp, followed by a row of small denticles. Otherwise similar to female.

\section{Host records}

Five specimens collected by B. Sigwald in 1962 emerged from lycaenid cocoons on Crotalaria sp. (Leguminosae); three of these cocoons have been found inside pods (new host record).
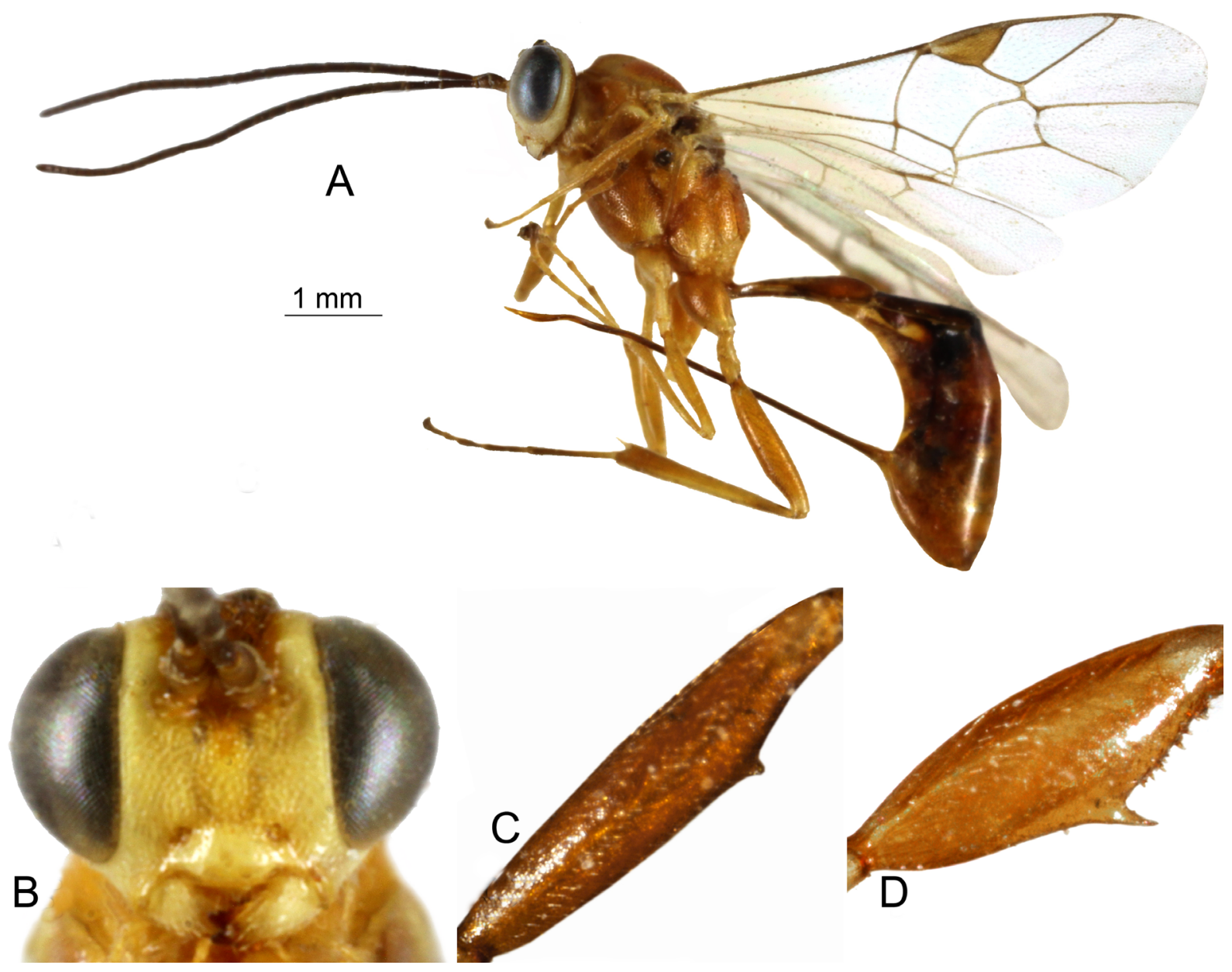

Fig. 5. Pristomerus cunctator Tosquinet 1896. A. $q$, habitus, profile. B. $q$, head, facial. C. + , hind femur, profile. D. $\overbrace{}^{\lambda}$, hind femur, profile. 


\section{Remarks}

This species exhibits a moderate variability in the color pattern, especially on the extension of the dark markings on mesosoma and metasoma. The specimens from Madagascar are noticeably lighter than those from mainland Africa, especially Namibia.

\section{Distribution}

Madagascar (Toliara and Toamasina province) (new distribution record). Mozambique and Senegal.

Pristomerus guinness sp. nov. urn:1sid:zoobank.org:act:EA0C6E7D-8920-401B-B023-154708106284

Fig. 6

\section{Diagnosis}

Large species; face ivory white; head white and black, mesosoma testaceous-orange, metasoma black with apical margin of tergites $2-7$ white; face densely punctate, clypeus transverse and sparsely punctate; entire mesosoma densely punctate-granulate; area superomedia about $2.5 \mathrm{x}$ longer than wide; female femoral tooth small; ovipositor moderately long, its apex sinuate; POL 0.6; OOL 0.7; CT 1.9; ML 0.6; OT 1.4-1.5; FFT 1.

\section{Differential diagnosis}

Species characterized by the black and white color pattern of metasoma, and the entirely densely punctate-granulate mesosoma.

\section{Etymology}

Refers to a great beer of similar color pattern.

\section{Type material}

\section{Holotype}

MADAGASCAR: ㅇ (MNHN EY3649), Rogez, 48¹8' S, 48³2' E, verbatim label data: “Madagascar, Rogez, forêt côte est, V. 32", complete.

\section{Paratypes}

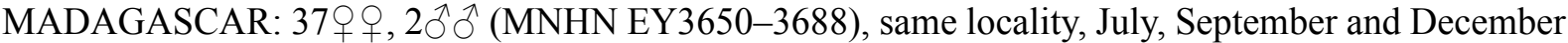
1930, January, February, May and November 1931, February, April-June, September, October, December 1932, November 1933, February and May 1936, March 1938, February 1940; 2 (CAS), Rogez, May 1931; 7옹 same locality, February 1930, February and May 1931 (one to each of the other above mentioned institutions); 19 (CAS), verbatim label data: "Toamasina Province, botanic garden near entrance to Andasibe Nat. Park, $18^{\circ} 55.58^{\prime}$ S, 48 $24.47^{\prime}$ E, 24 Oct-1 Nov 2001, Malaise trap MA-01-08B-17, in tropical forest, elev. 1025m, Irwin \& Harin'Hala coll.”

\section{Other material examined}

MADAGASCAR: 11우으수 (MNHN), Rogez, February 1930 and 1936, January, April-May 1932, 1935, May 1936 and 1938; $1 \overbrace{}^{\Uparrow}$ (MNHN), Ivondro, March 1940.

\section{Description}

\section{Female}

Length. 6.5, 5.9 (4.9-6.7) (10 specimens). 
HEAD. Strongly constricted behind eyes. Temple very short. Vertex finely granulate and sparsely punctate. Ocellar triangle equilateral. Frons smooth with basal transverse striation and a distinct longitudinal ridge from the central ocellus. Face subrectangular, shining, more densely punctate centrally than laterally. Clypeus moderately transverse, smooth with sparse punctures. Mandible stout, teeth subequal. Malar line rather short. Antenna with 35-36 flagellomeres.

Mesosoma. Moderately elongate, nearly 2 x longer than high. Pronotum, mesonotum, mesopleuron and metapleuron densely punctate-granulate. Speculum punctate with a narrow smooth ventral area. Notaulus strongly impressed. Propodeum long, densely punctate, area petiolaris transversally wrinkled, area basalis opposite or slightly truncate, area superomedia about $2.5 \mathrm{x}$ longer than wide, about as long as area petiolaris. Legs: femoral tooth reduced but distinct, followed by a row of small tubercles.

Metasoma. Tergite 1 almost smooth, post-petiole and tergite 2 finely aciculate, the following tergites finely granulate. Tergite 2 , about $0.7 \mathrm{x}$ as long as tergite 1 , about $2.5 \mathrm{x}$ longer than apically wide. Ovipositor moderately long and sinuate at apex.

CoLor. Head ivory white with frons, vertex, temple, occiput, posterior half of gena, and a small triangle under toruli black. Antenna basally black, fading to testaceous from flagellomere 3 but two apical flagellomeres darker. Mesosoma and legs testaceous orange. Metasoma black, tergites 2 and following largely white apically. Wings hyaline, densely hairy, pterostigma dark brown.
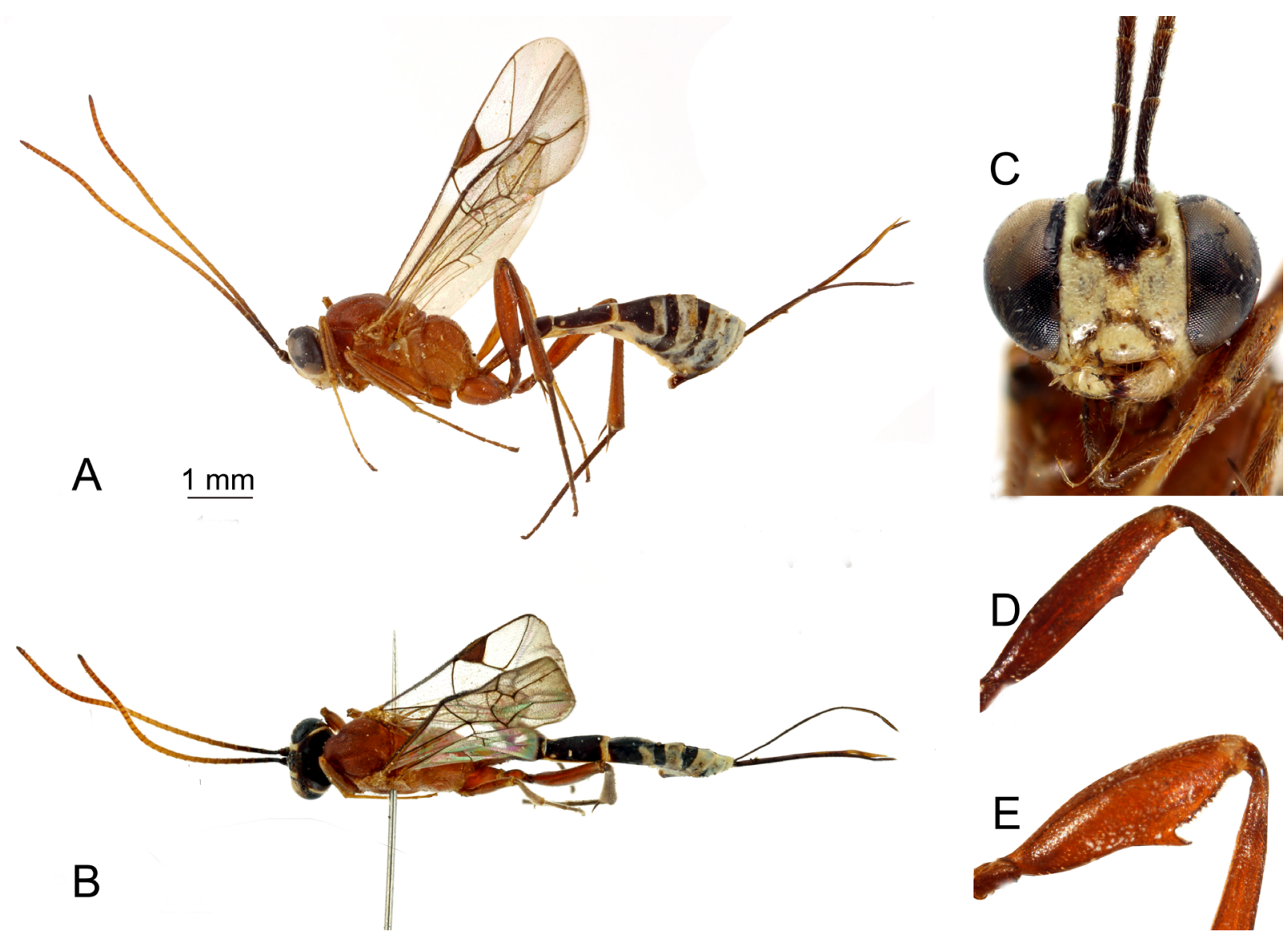

Fig. 6. Pristomerus guinness sp. nov. A. $甲$, habitus, profile. B. $\odot$, habitus, dorsal. C. $\odot$, head, facial. D. + , hind femur, profile. E. $\widehat{\jmath}$, hind femur, profile. 


\section{Male}

Length: 6.7 (6.3-7.1) (2 specimens). Posterior ocellus almost touching eyes dorsally (OOL $=0.1$; POL $=0.4$ ). Hind femur swollen with a stout and pointed tooth, followed by a row of denticles. Otherwise similar to female.

\section{Distribution}

Madagascar (Toamasina province).

$$
\begin{gathered}
\text { Pristomerus hansoni sp. nov. } \\
\text { urn:1sid:zoobank.org:act:3D8B6B52-CE8C-46CC-BD44-12F0015DB181 }
\end{gathered}
$$

Fig. 7

\section{Diagnosis}

Large species; face ivory white; head white and black, mesosoma and metasoma orange; face transverse and almost smooth with sparse punctures, clypeus slightly transverse, smooth; mesoscutum moderately punctate-granulate, scutellum sparsely punctate; area superomedia about $3 \mathrm{x}$ longer than wide; female femoral tooth absent; ovipositor very long, its apex sinuate; POL 0.7; OOL 0.8; CT 1.5; ML 0.6; OT 2.8-3.2; FFT 0.

\section{Differential diagnosis}

Species closely related to $P$. caris, from which it differs by the characters given in the key; the ovipositor is strikingly longer than in any other Pristomerus species in Madagascar.

\section{Etymology}

Dedicated to Ace Hanson.

\section{Type material}

\section{Holotype}


Rogez, forêt côte est, XII. 30", left antenna lacking.

\section{Paratypes}

MADAGASCAR: 20 우, 5 $ぇ$ (MNHN EY3621-3645), same locality, Sep. and Dec. 1930, Jan., Feb., May, Nov. and Dec. 1931, Feb. 1932; 1 q (MNHN EY3646), Andreba, Nov. 1933; 1 \&, 1 के (MNHN EY3647-3648), Ivondro, Jan. 1939; 8 우 (CAS), Rogez, Dec. 1931; 7 우, Rogez, Dec. 1930, Jan., Nov. 1931 (one to each of the other above mentioned institutions).

\section{Other material examined}

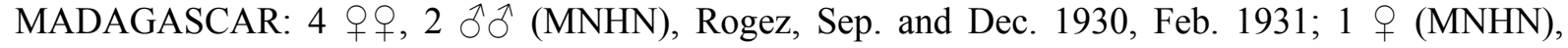
Andreba, Nov. 1933.

\section{Description}

\section{Female}

LENGTH. 5.5, 6.1 (5.5-6.7) (10 specimens).

Head. Strongly constricted behind eyes. Temple very short. Ocellar triangle equilateral. Vertex and frons granulate with sparse punctures. Face rectangular, almost $2 \mathrm{x}$ wider than long, almost smooth with sparse punctures. Frons mid-longitudinally bulging, finely granulate and sparsely punctate. Clypeus 
smooth, slightly transverse. Mandible stout and moderately long, malar line rather short. Antenna thin with 33-39 flagellomeres. Flagellomere 1 about 6 x longer than apically wide.

Mesosoma. Moderately elongate, about $2 \mathrm{x}$ longer than high. Pronotum and speculum smooth. Mesoscutum moderately punctate-granulate, shining. Scutellum smooth with sparse punctures. Mesopleuron more sparsely punctate, almost smooth between punctures. Metapleuron granulate. Propodeum long, shining, its surface finely granulate and sparsely punctate. Area basalis opposite or truncate, area superomedia $3 \times$ longer than wide, area petiolaris as long as superomedia. Legs: elongate, hind femur slender, femoral tooth absent.

Metasoma. Tergites 1 and 2 finely aciculate, following tergites alutaceous. Tergite 2 as long as tergite 1 and about $2 \times$ longer than wide. Ovipositor very long with its apical $1 / 3$ conspicuously sinuate.

CoLor. Orange overall with flagellum and ovipositor sheath brownish. Head ivory white with frons centrally, vertex and occiput dark brown. Wings hyaline, pterostigma orange.

\section{Male}

Length: $5.6(4.7-6.3)$ (7 specimens). Ocellus large; posterior ocelli closer to eyes $(\mathrm{OOL}=0.2)$ than to each other $(\mathrm{POL}=0.3)$. Mesosoma smoother. Hind femur with a sharp ventral tooth followed by a row of denticles, hind tibia longer and stouter, widened apically. Otherwise similar to female.

\section{Distribution}

Madagascar (Toamasina and Antsiranana province).
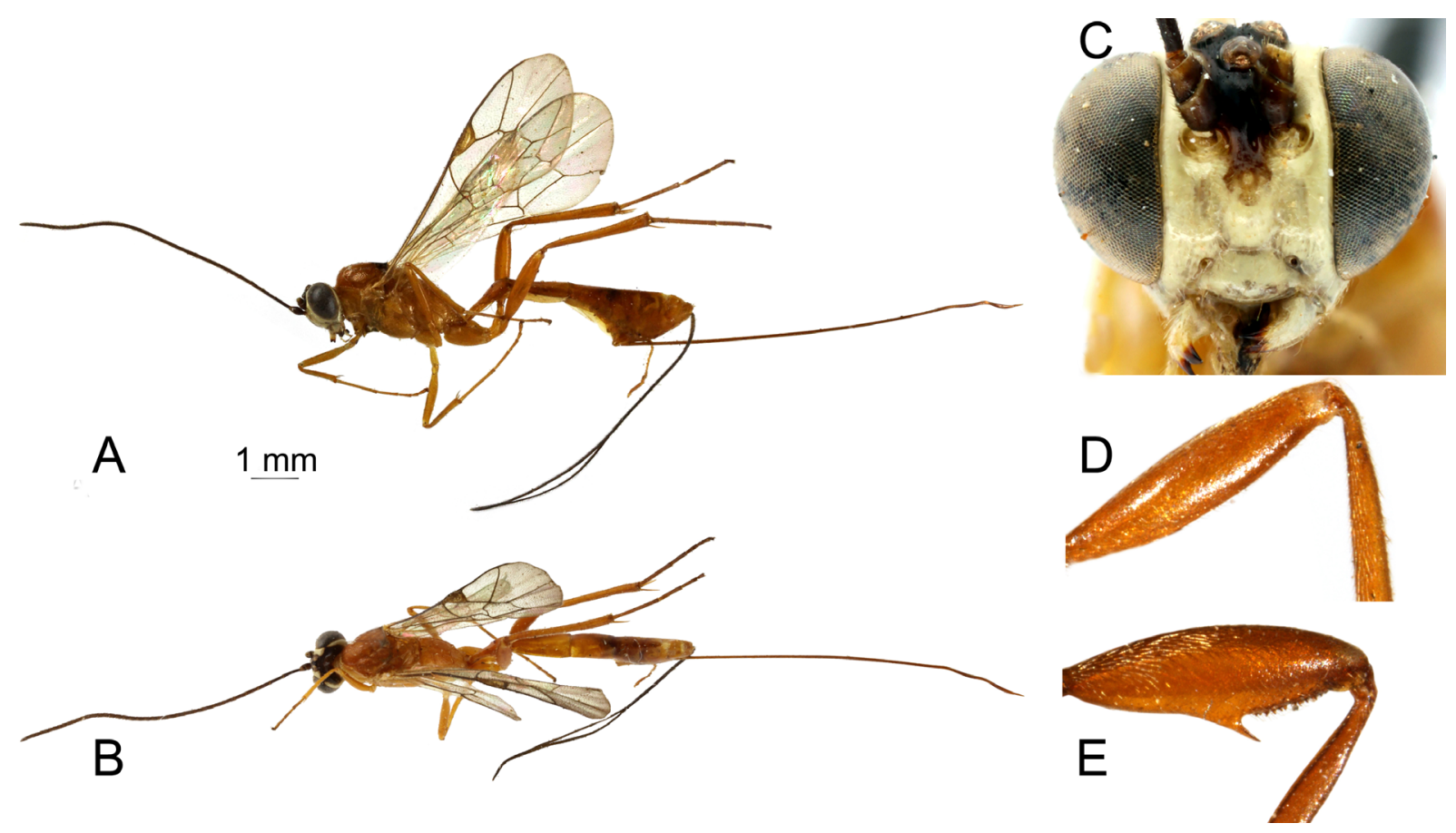

Fig. 7. Pristomerus hansoni sp. nov. A. + , habitus, profile. B. + , habitus, dorsal. C. $q$, head, facial. D. $\rightarrow$, hind femur, profile. E. $\widehat{\jmath}$, hind femur, profile. 
Pristomerus kelikely sp. nov. urn:1sid:zoobank.org:act:51FCD577-630D-4405-9F34-571A3EB7DB2F

Fig. 8

\section{Diagnosis}

Small species; face orange; general coloration orange; face moderately and finely punctate, clypeus transverse and sparsely punctate; mesoscutum densely punctate medially, apical margin of lateral lobe smooth, scutellum smooth; area superomedia about 2 x longer than wide; female femoral tooth absent; ovipositor moderately long, apically sinuate; POL 0.8 ; OOL 1.3; CT 2.0; ML 0.6; OT 1.5-1.8; FFT 0.

\section{Differential diagnosis}

The combination of small size, orange face, absence of femoral tooth in female and hardly enlarged ocelli in male makes this species readily distinguishable from any other in Madagascar but P. moramora. Both may be differentiated by characters given in the key.

\section{Etymology}

Euphonic reference to the small size of this species: "kely" is the Malagasy word for "little".

\section{Type material}

\section{Holotype}

MADAGASCAR: + (MNHN EY2477), Anivorano, 164' S, 48¹0’ E, verbatim label data: "Madagascar, Anivorano, XII 1929”, hind tarsi and half right antenna lacking.
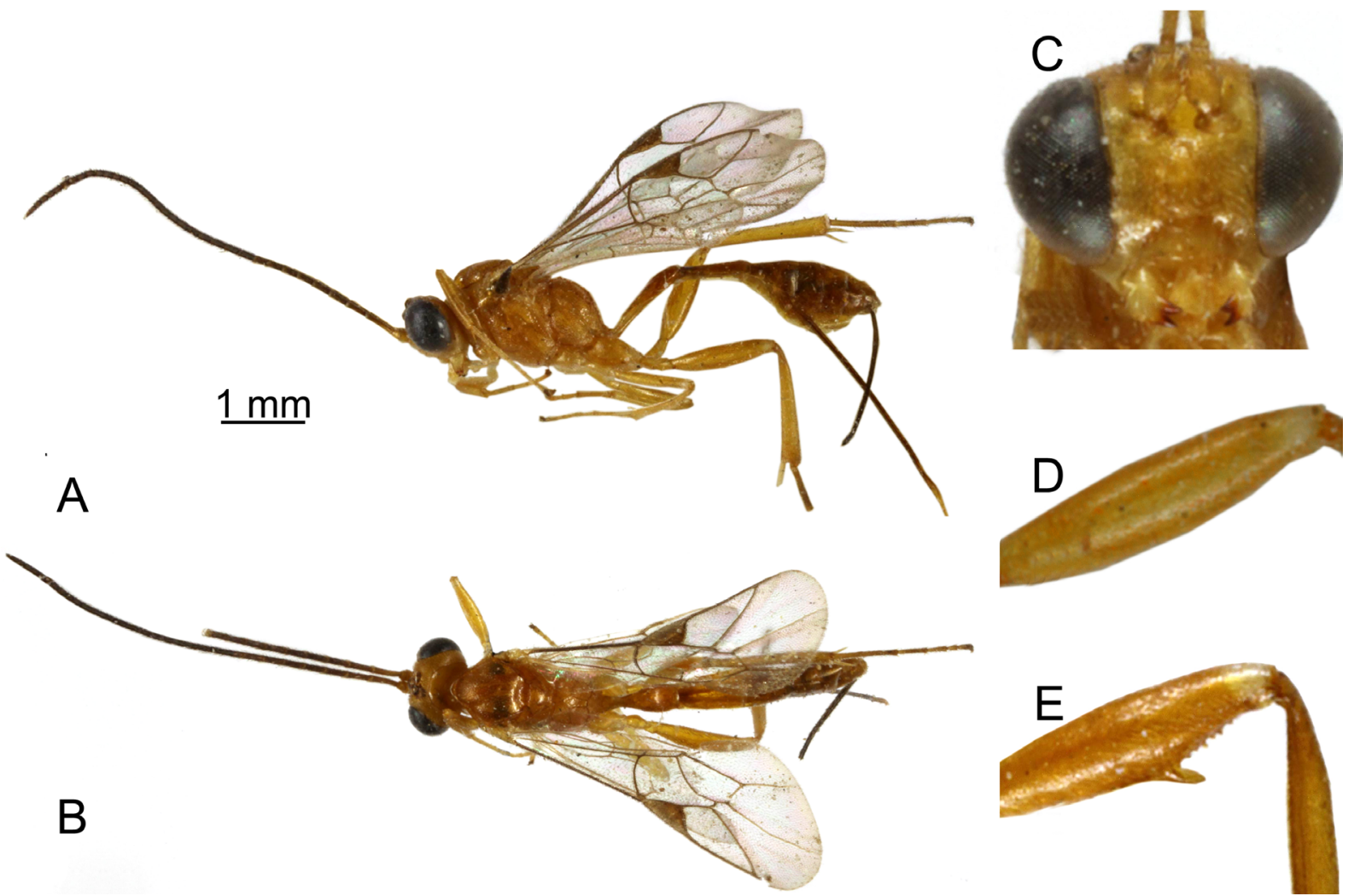

Fig. 8. Pristomerus kelikely sp. nov. A. $q$, habitus, profile. B. $q$, habitus, dorsal. C. $q$, head, facial. D.



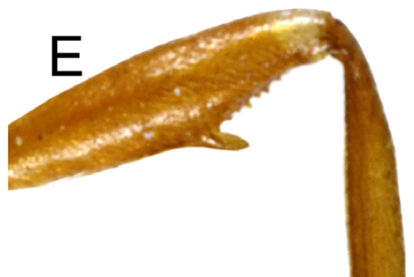




\section{Paratypes}

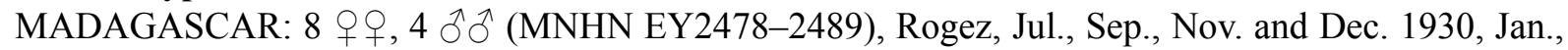
Feb. and Nov. 1931; 3 ㅇ $q$ (BNHM, MRAC, IZPAN), Rogez, Sep. and Oct. 1930; 1 ( (MNHN EY8697), Antanimora, Jan. 1937; 2 우 (ISAM, MNHU), same locality, same date; 2 우 ${ }^{2} 2{ }^{\lambda}{ }^{\lambda}$ (MNHN EY86998702), Ivondro, Oct. 1936, Dec. 1938 and May 1940; 1 ㅇ, 1 § (ANHM, NHRS), same locality, Dec.

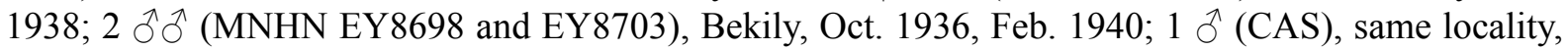
Oct. 1936.

\section{Description}

\section{Female}

LENGTH. 4.0, 4.0 (3.2-4.3) (10 specimens).

HeAd. Constricted behind eyes. Temple, vertex and frons granulate. Ocellar triangle equilateral. Face shining, moderately and finely punctate. Clypeus transverse, sparsely punctate. Mandible rather short, stout, teeth subequal. Malar line rather short. Antenna with 31-32 flagellomeres; first flagellomere $1.2 \times$ longer than second.

Mesosoma. Elongate, about $2 \mathrm{x}$ as long as high, shining. Pronotum nearly smooth. Mesoscutum densely punctate, lateral lobe smoother, its apical margin quite smooth. Scuto-scutellar groove longitudinally ribbed. Scutellum slightly convex, almost smooth. Pleurae moderately punctate, speculum smooth. Propodeum moderately to densely punctate laterally, smoother medially. Area basalis opposite, sometimes truncate or petiolate, area superomedia about $2 \times$ longer than wide. Legs: femoral tooth absent.

Metasoma. Tergites 1 and 2 finely aciculate. Tergite 2 as long as tergite 1 , about $2 \mathrm{x}$ longer than apically wide. Ovipositor moderately long, apex slightly sinuate.

CoLor. Orange overall. Flagellum black. First tergites slightly fuscous. Wings hyaline, pterostima yellowish-brown.

\section{Male}

Length: 3.9 (3.2-4.7) (5 specimens). Ocelli not enlarged, rather distant from eyes $(\mathrm{OOL}=1.0)$. Area superomedia more variable in size. Femur stouter, femoral tooth strong and sharp. Otherwise similar to female.

\section{Distribution}

Madagascar (Toamasina province).

$$
\begin{aligned}
& \text { Pristomerus keyka sp. nov. } \\
& \text { urn:1sid:zoobank.org:act:106A9CD2-DB8C-4726-9BEE-5B0C458A285E }
\end{aligned}
$$

Fig. 9

\section{Diagnosis}

Small species; face orange; general coloration yellow to orange with infuscate markings; antennae short (23 flagellomeres); face and clypeus smooth with sparse punctures; mesonotum granulate; area superomedia about $2 \times$ longer than wide; female femoral tooth small; ovipositor long, apically sinuate; POL 0.5; OOL 0.8; CT 2.0; ML 0.8; OT 1.8-2.0; FFT 1.

\section{Differential diagnosis}

Species mainly characterized by the quite short antennae with 23 flagellomeres and the very weak microsculpture. 


\section{Etymology}

Euphonic arrangement of letters.

\section{Type material}

\section{Holotype}

MADAGASCAR: + (CAS), Namoraka National Park, $16^{\circ} 28^{\prime} \mathrm{S}, 45^{\circ} 20^{\prime}$ E, verbatim label data: "Madagascar, Mahajanga Province, Parc Nat Namoraka, November 2002 (colls Fisher, Griswold et al.), in tropical dry forest, California Academy of Sciences", left median tibia, left hind tarsi and left antenna lacking.

\section{Paratype}

MADAGASCAR: 1 ( (MNHN EY2493), same date and same locality. Ovipositor broken.

\section{Description}

\section{Female}

LeNGTH. 3.1, 3.0 (2.8-3.1) (2 specimens).

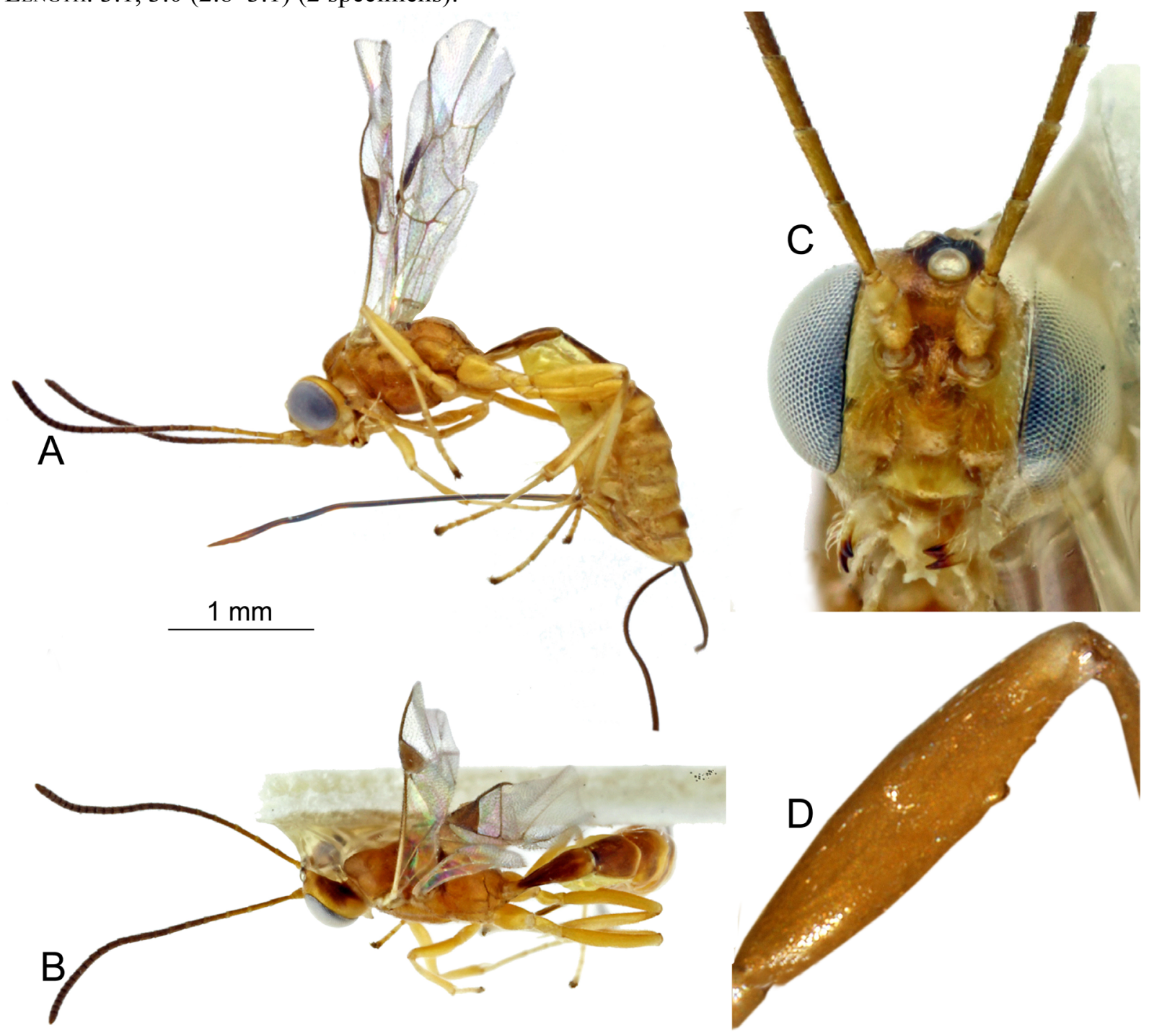


hind femur, profile. 
HEAD. Frons, face and clypeus almost smooth with sparse punctures. Clypeus transverse and convex. Mandibular teeth subequal. Malar line moderately long. Ocellar triangle equilateral. Antenna short with 23 flagellomeres.

Mesosoma. Slightly elongate, about $1.7 \mathrm{x}$ longer than high. Pronotum sparsely punctate. Mesonotum as long as wide, granulate with sparse puncture along notaulus. Pleurae and propodeum densely punctategranulate. Area basalis triangular, petiolate or opposite, area superomedia about $2 \times$ longer than wide. Legs: femoral tooth distinct but small.

Metasoma. Post-petiole and tergite 2 finely aciculate. Tergite 2 about $1.5 \mathrm{x}$ longer than apically wide. Ovipositor long, apically distinctly sinuate.

CoLor. Holotype mainly orange. Yellow: upper part of orbits, gena, mandible, trochanters, tibiae and tarsi. Ocellar triangle and metanotum infuscate. Flagellum infuscate, orange at base, scape and pedicel orange. Wings hyaline, pterostima brown with an ivory white anterior margin. Tergites 1-3 brown, apically yellow, the following tergites yellow with a mid-longitudinal infuscate stripe. Paratype with coloration much lighter: base of antenna, legs and metasoma from tergite 4 entirely yellow.

\section{Male}

Unknown.

\section{Distribution}

Madagascar (Mahajanga province).

$$
\begin{aligned}
& \text { Pristomerus melissa sp. nov. } \\
& \text { urn:1sid:zoobank.org:act:B55B6446-DBE7-4EC1-95B7-90F2798D1EC0 }
\end{aligned}
$$

Fig. 10

\section{Diagnosis}

Moderately large species; face black; head black and white; general coloration testaceous-orange with tergite 1, basal half of tergite 2 and apico-lateral margins of mesoscutum black; face densely punctategranulate, clypeus transverse and smooth; mesonotum densely punctate-granulate; area superomedia laterally not delimited; female femoral tooth small; ovipositor short, its tip slightly sinuate; POL 0.7; OOL 1.0; CT 2.0; ML 0.8; OT 1.0; FFT 1.

\section{Differential diagnosis}

Species highly characteristic on account of the head color, the relatively short ovipositor and the laterally not delimited area superomedia.

\section{Etymology}

Euphonic arrangement of letters.

\section{Type material}

\section{Holotype}

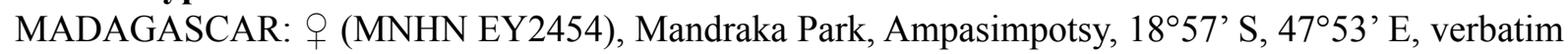
label data: "Madagascar, Mandraka forest, IV.32", complete.

\section{Description}

\section{Female}

LENGTH. 5.1. 
HEAD. Face mid-longitudinally bulging, densely punctate-granulate with very fine pilosity. Clypeus almost smooth with few punctures. Ocellar triangle equilateral. Mandible moderately long, teeth subequal. Malar line moderately long. Antenna with 35 flagellomeres.

Mesosoma. Moderately elongate, $2 \mathrm{x}$ longer than high. Pronotum smooth, its postero-dorsal edge granulate. Mesonotum densely punctate-granulate. Mesopleuron and metapleuron shining, densely punctate. Propodeum long, densely punctate. Area basalis triangular, strongly petiolate. Lateral carinae of area superomedia lacking. Legs: long and thin, hind femur with a small tooth.

Metasoma. Tergites 1 almost smooth, post-petiole and tergite 2 finely aciculate. Tergite 2 almost as long as tergite 1 and about $2 \mathrm{x}$ longer than apically wide. Ovipositor relatively short, slightly up-curved and briefly sinuate at apex.

CoLOR. Head blackish brown with clypeus, malar space and mandible pale yellow. Mandibular teeth and antennae dark brown. Mesosoma testaceous-orange, dorso-laterally slightly infuscate. First tergite blackish. Second tergite with basal half yellow, apical half black with a yellow margin. Remainder of metasoma testaceous-orange. Legs orange, hind tibia (basally) and hind tarsus darker. Wings hyaline, pterostigma and ovipositor sheath dark brown.
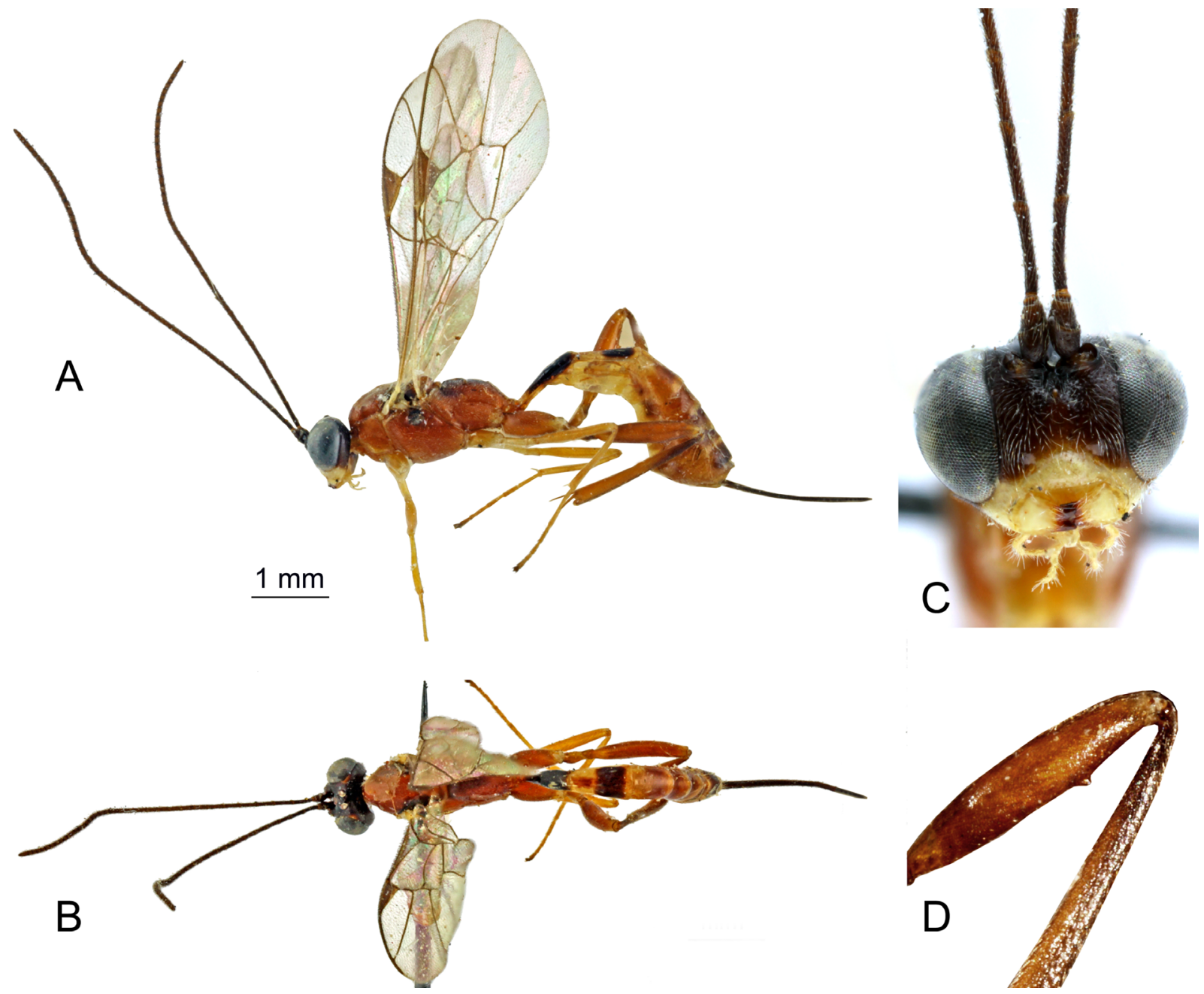

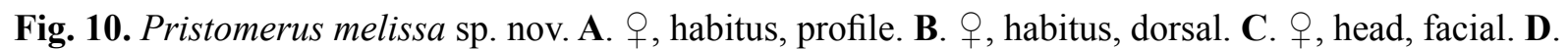
q, hind femur, profile. 


\section{Male}

Unknown.

\section{Distribution}

Madagascar (Toamasina province).

$$
\begin{gathered}
\text { Pristomerus moramora sp. nov. } \\
\text { urn:1sid:zoobank.org:act:B28A821C-3528-49BE-A496-46814BE45360 }
\end{gathered}
$$

Fig. 11

\section{Diagnosis}

Small species; face yellow; general coloration yellow-orange with large more or less dark brown markings of variable extension; face sparsely punctate, clypeus transverse and smooth; mesoscutum moderately to densely punctate-granulate, scutellum sparsely punctate; area superomedia about $2.5 \mathrm{x}$ longer than wide; female femoral tooth absent; ovipositor moderately long, its apex sinuate; POL 0.9; OOL 1.2; CT 2.2; ML 0.5; OT 1.6-1.8; FFT 0.

\section{Differential diagnosis}

cf. P. kelikely and P. albescens.

\section{Etymology}

"Mora mora" is an indispensable expression in Madagascar meaning "take it easy".

\section{Type material}

\section{Holotype}


"Madagascar, Bekily [Ampandrandava], reg. sud de l'île, IX 1938", complete.

\section{Paraptypes}

MADAGASCAR: 1 +, 2 $\widehat{\partial} \widehat{\partial}$ (MNHN EY2496-2498), same locality, same date; 7 우, 3 $\widehat{\partial}$ (MNHN EY8704-8713), same locality, Jul., Sep.-Oct. 1936, Apr., Aug.-Sep. 1938; 1 + (MNHN EY8714), Tulear [Toliara], no sampling date (Cathala coll.); 4 우, 4 ô $\widehat{\partial}$, Bekily, Oct. 1936 (one specimen to each of the above mentioned institutions).

\section{Other material examined}


Behora, Mar. 1938.

\section{Description}

\section{Female}

LeNGTH. 3.5, 3.2 (2.8-3.5) (10 specimens).

HeAd. Strongly constricted behind eyes. Temple short and rounded. Ocellar triangle anteriorly acute. Face slightly narrowed ventrally. Frons and vertex shallowly punctate-granulate, face shining, sparsely punctate. Clypeus transverse, almost smooth. Mandible short and stout, teeth subequal, malar line short. Antenna with 27-29 flagellomeres.

Mesosoma. Slightly elongate, about $1.7 \mathrm{x}$ longer than high. Pronotum almost smooth. Remaining of mesonotum covered with short white adpressed hairs. Mesoscutum shining, densely to moderately 
punctate-granulate, smoother posteriorly. Scuto-scutellar groove with longitudinal striation. Scutellum shining, sparsely punctate, its vertical posterior margin longitudinally striate. Mesopleuron and metapleuron shining and moderately punctate, speculum smooth. Propodeum shining, sparsely punctate, area petiolaris transversally wrinkled posteriorly. Area basalis opposite, sometimes petiolate or shortly truncate, area superomedia $2.5 \mathrm{x}$ longer than wide, distinctly narrower and about as long as area petiolaris. Legs: femoral tooth absent.

Metasoma. Post-petiole and tergite 2 finely aciculate, the following tergites alutaceous. Tergite 2 a little shorter than tergite 1 , about $2.5 \mathrm{x}$ longer than apically wide. Thyridia narrow, elongate oval. Ovipositor rather long and slightly sinuate at apex.

CoLor. Antenna brown, scape and pedicel orange ventrally. Head and mesosoma yellowish-orange with more or less extended brown markings. Face, inner orbits and gena yellow. Brown: frons, ocellar triangle, lobes of mesonotum, a large macula on mesopleuron and metapleuron, scuto-scutellar groove, dorsal face (and sometimes lateral margins) of scutellum, basal part of propodeum, including entire area superomedia and areae dentiparae. In some individuals, the median lobe of mesoscutum, and the scutellum are light brown. Legs yellowish-orange, front and mid trochanters white. Hind leg with coxa, femur, basal and apical margins of tibia, and tarsus infuscate, hind tibia mid-dorsally white. Wings hyaline, pterostigma brown. Metasoma brown, base of tergite 1 orange, post-petiole and other tergites dorsally dark brown and more or less marked with orange posteriorly. Thyridia yellow. Ovipositor sheath brown.
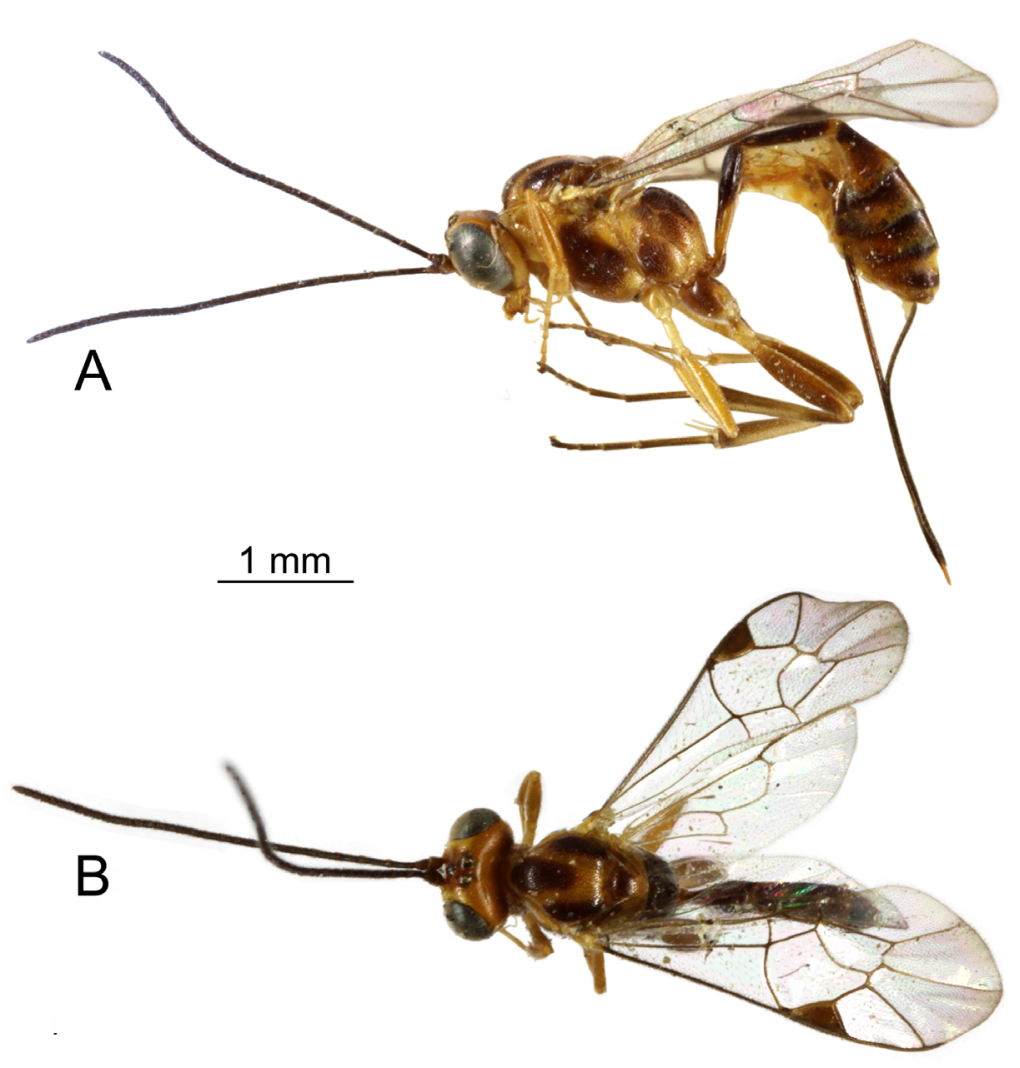
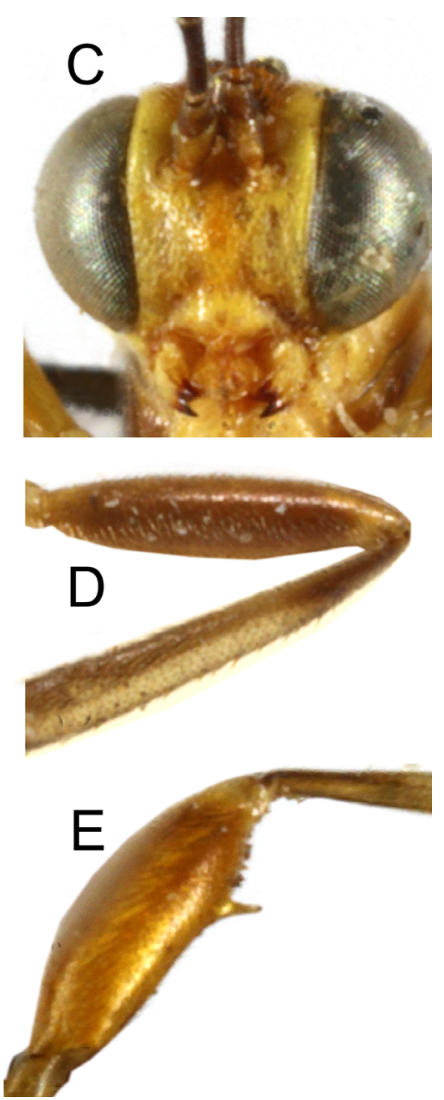

Fig. 11. Pristomerus moramora sp. nov. A. $q$, habitus, profile. B. $\uparrow$, habitus, dorsal. C. $q$, head, facial. D. $q$, hind femur, profile. 


\section{Male}

Length: 3.1 (2.6-3.5) (6 specimens). Posterior ocelli equally distant from each other as from eye (POL $=\mathrm{OOL}=1.0$ ). Face not narrowed ventrally. Hind femur swollen, femoral tooth long, followed by a row of denticles. Otherwise similar to female.

\section{Remarks}

Five specimens $(4+q, 1 \lesssim$ ) with a larger (L: 3.7-3.9) and lighter body have been related to P. moramora but not included in the type series: they have identical ocellar indices, the same number of flagellomeres and a similar microsculpture; however, the base of petiole is yellow, the mesosoma and metasoma from the fourth tergite are entirely orange, and the ovipositor is longer $(\mathrm{OT}=1.9-2)$, perhaps due to allometry.

\section{Distribution}

Madagascar (Toliara province).

Pristomerus patator sp. nov. urn:Isid:zoobank.org:act:EE8F3E6A-9990-4CA0-94B7-08BFC358EB4A

Fig. 12

\section{Diagnosis}

Large species; face yellowish-orange; general coloration yellowish-orange with some median dark spots on metasomal tergites; face densely punctate, clypeus slightly transverse and smooth; mesonotum densely punctate; area superomedia about $2.5 \mathrm{x}$ longer than wide, laterally hardly delimited; tergite 1 smooth, tergite 2 hardly sculptured; female femoral tooth small; ovipositor long, apically sinuate; POL 0.6; OOL 1.0; CT 1.6; ML 0.8; OT 1.7-1.9; FFT 1.

\section{Differential diagnosis}

Species closely related to $P$. roberti, characterized by the dense punctation of face, the propodeum with area superomedia hardly delimited laterally and the almost smooth second metasomal tergite.

\section{Etymology}

Euphonic arrangement of letters.

\section{Type material}

\section{Holotype}


"Madagascar, Bekily [Ampandrandava], reg. sud de l'île, XII.33", complete.

\section{Paratypes}

MADAGASCAR: 3 우, 2 $\widehat{\jmath}$ (MNHN EY3502-3506), same locality, Dec. 1930, Jan., Mar. and Dec. 1933.

\section{Description}

\section{Female}

LeNGTH. 5.9, 6.9 (5.9-7.5) (4 specimens).

Head. Strongly constricted behind eyes. Vertex and temple finely granulate. Ocellar triangle equilateral. Frons laterally punctate-granulate, centrally smooth, mid-longitudinally bulging. Face midlongitudinally bulging, punctate, punctures sparser centrally and along inner orbits. Clypeus shining, 
almost unpunctate, slightly transverse. Mandible stout and curved. Malar line moderately long. Antenna with 37-38 flagellomeres.

Mesosoma. Slightly elongate, about $1.7 \mathrm{x}$ longer than high. Pronotum smooth. Mesonotum shining, densely punctate. Mesopleuron shining, more sparsely punctate, speculum smooth. Scutellum almost smooth. Propodeum densely punctate, area basalis truncate, area superomedia about 2.5 longer than wide, laterally hardly delimited. Legs: femoral tooth present but small.

Metasoma. Shining. Tergite 1 almost smooth. Tergite 2 with shallow aciculation and sparse punctures. Following tergites alutaceous. Tergite 2 about $2.5 \mathrm{x}$ longer than apically wide. Ovipositor moderately long, its apical third slightly sinuate.

CoLor. Yellowish-orange overall with some median dark spots on metasomal tergites, flagellum and metasoma infuscate. Wings hyaline, pterostigma orange.

\section{Male}

Length: 6.5 (6.3-6.7) (2 specimens). Ocellar triangle large, oculo-ocellar distance $(\mathrm{OOL}=0.4)$ shorter than inter-ocellar distance $(\mathrm{POL}=0.6)$. Hind femur stouter, femoral tooth stout followed by a row of rather strong tubercles. Otherwise similar to female.
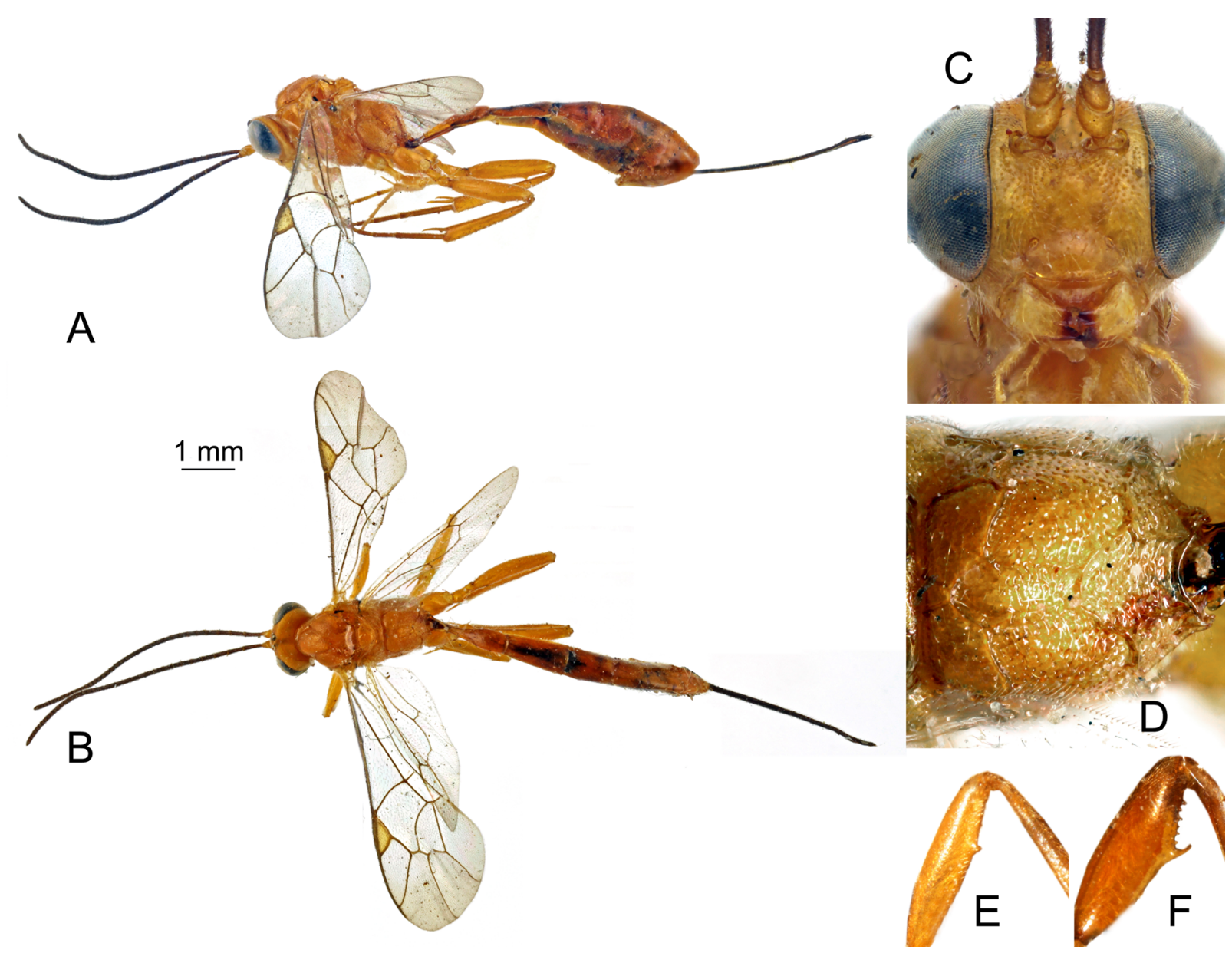

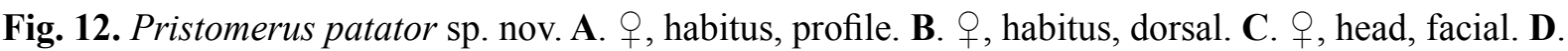
+, propodeum, dorsal. E. $\odot$, hind femur, profile. F. Oे $^{\lambda}$ hind femur, profile. 


\section{Distribution}

Madagascar (Toliara province).

\section{Pristomerus ranomafanana sp. nov. urn:1sid:zoobank.org:act:243C09D4-1FA5-44D2-BD05-04ED01656E1F}

Fig. 13

\section{Diagnosis}

Moderately large species; face black; head white and black, mesosoma rufo-testaceous with black markings, metasoma orange brown, tergite 2 and apex of tergite 1 black, following tergites dorsally brown; face moderately punctate-granulate, clypeus transverse and smooth; mesoscutum densely punctate-granulate, apically smoother, scutellum almost smooth; area superomedia about $2 \times$ longer than wide; female femoral tooth absent; forewing with 2 rs-m $4 \mathrm{x}$ shorter than the section of M separating 2rs-m and 2m-cu; ovipositor long, apically sinuate; POL 1.0; OOL 1.3; CT 1.8; ML 0.6; OT 2.2; FFT 0.

\section{Differential diagnosis}

Species superficially close to $P$. caris and related species with white face, distinguishable by the dark color pattern, the longer ovipositor and the very short vein $2 \mathrm{rs}-\mathrm{m}$.

\section{Etymology}

Euphonic reference to the collection place.

\section{Type material}

\section{Holotype}

MADAGASCAR: $q$ (CAS), Ranomafana National Park, $21^{\circ} 14^{\prime} \mathrm{S}, 47^{\circ} 25^{\prime} \mathrm{E}$, verbatim label data: "Madagascar, Province Fianarantsoa, Parc Nat. Ranomafana, $21^{\circ} 15.05^{\prime}$ S, $47^{\circ} 24.43^{\prime}$ E, mixed tropical
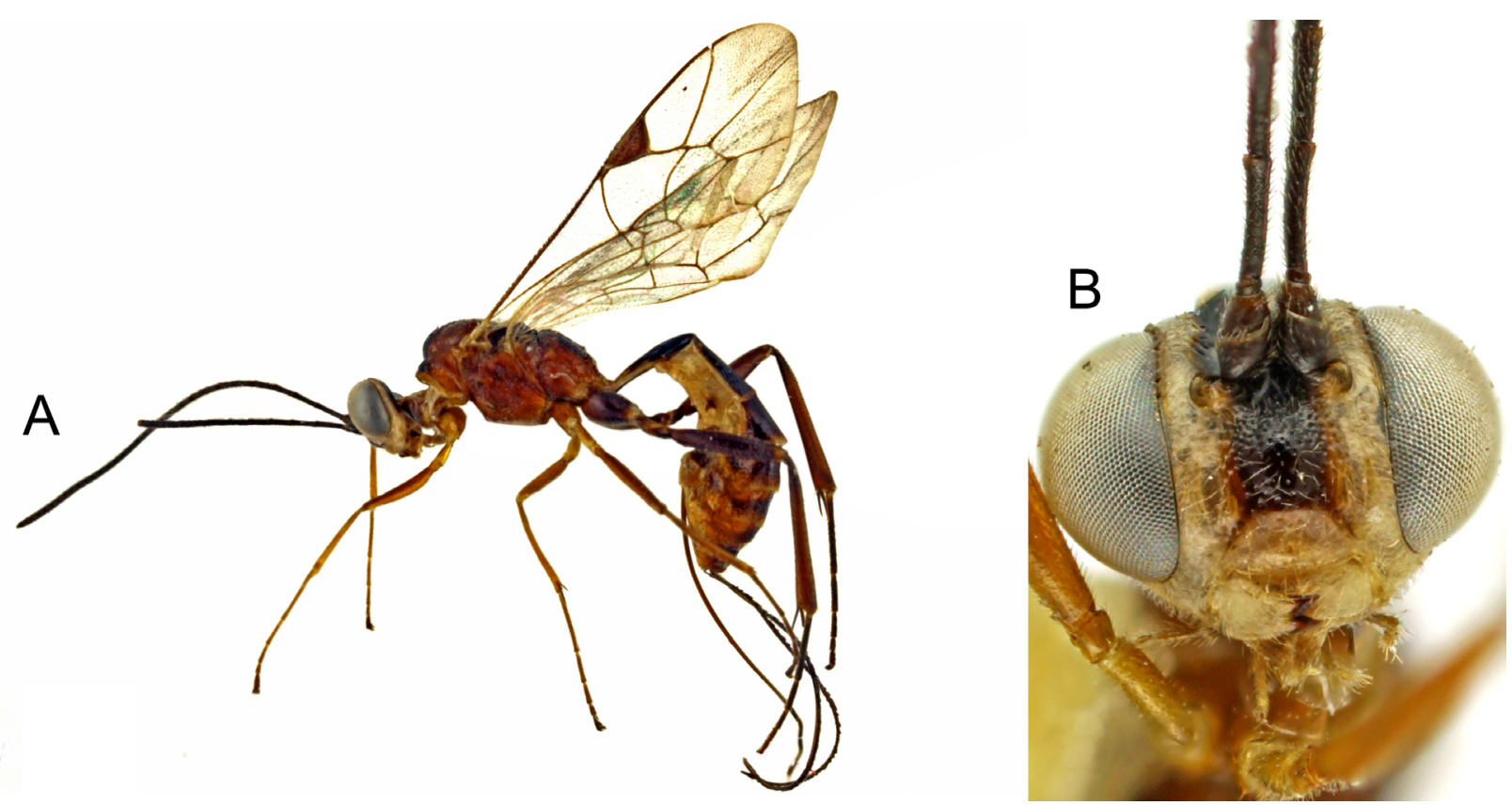

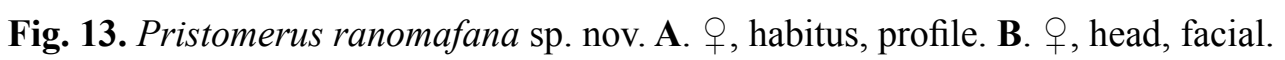


forest (radio tower) - 1130 m, 14-21 / I / 2002, Irwin \& Harin'Hala colls, California Academy of Sciences, Malaise trap MA-02-09B-12)", right antenna medially broken.

\section{Description}

Female

LENGTH. 4.9.

HEAD. Strongly constricted behind eyes. Temple very short, finely granulate. Vertex granulate. Ocellar triangle almost equilateral. Frons granulate. Face moderately punctate-granulate (punctures sparser laterally), slightly bulging mid-longitudinally. Clypeus almost unpunctate, slightly transverse. Malar line rather short. Mandible short and stout. Face, clypeus, mandible and vertex with sparse white pilosity. Antenna with 31 flagellomeres.

Mesosoma. Moderately elongate, $1.8 \mathrm{x}$ longer than high. Mesoscutum and pleurae densely punctategranulate anteriorly, smoother posteriorly. Pronotum almost smooth centrally, epomia distinct. Scutellum smooth with some punctures. Speculum almost smooth. Propodeum shining, densely punctate. Area basalis opposite, area superomedia $2 \mathrm{x}$ as long as wide. Propodeum, pleurae and ventral margin of coxae covered with white hairs. Wings: fore wing with vein $2 \mathrm{rs}-\mathrm{m}$ very short, about $0.3 \mathrm{x}$ as long as $2 \mathrm{~m}-\mathrm{cu}$, and basal to $2 \mathrm{~m}-\mathrm{cu}$ by $4 \mathrm{x}$ its length. Legs: long and thin, without a distinct tooth on hind femur.

Metasoma. Post-petiole, tergite 2 and base of tergite finely aciculate. Tergite 1 slightly longer than tergite 2 . Tergite 2 about 3 x longer than apically wide. Post-petiole almost flat. Glymma long. Ovipositor long and thin, its apex strongly sinuate.

CoLor. Head ivory white with black markings. Black: antennae, center of face and frons, vertex, occiput, posterior half of outer orbit and a dorsal spot crossing the orbit. Mesosoma rufo-testaceous with black marking on median lobe of mesoscutum, scuto-scutellar groove, lateral sides of scutellum, post-scutellum and dorsal face of propodeum. Metasoma orange brown. Tergite 1 basally and laterally yellow. Postpetiole and tergite 2 black, the following tergites dorsally brown. Fore and mid legs pale brown with femora slightly darker. Hind legs blackish-brown, tibia slightly paler. Wings hyaline, pterostigma dark brown. Ovipositor sheath dark brown.

\section{Male}

Unknown.

\section{Distribution}

Madagascar (Fianarantsoa province).

$$
\begin{gathered}
\text { Pristomerus roberti sp. nov. } \\
\text { urn:1sid:zoobank.org:act:D0610706-1D96-4E5C-9019-71BFEB50B1D8 }
\end{gathered}
$$

Fig. 14

\section{Diagnosis}

Moderately large species; face orange; general coloration testaceous-orange with tergites 2-3 and apex of tergite 1 blackish brown; face at least latero-medially punctate, clypeus strongly transverse and granulate; mesoscutum densely punctate (almost smooth in male), scutellum moderately punctate; area superomedia about $2 \times$ longer than wide; female femoral tooth small; ovipositor long, apically sinuate; POL 0.9; OOL 1.2; CT 2.5; ML 0.4; OT 2.2; FFT 1. 


\section{Differential diagnosis}

Species closely related to $P$. cunctator, distinguishable by the color pattern and the longer ovipositor. The mesonotum of $P$. roberti is uniformly orange, without any yellowish orange markings on notauli and scutellum.

\section{Etymology}

Named for Thierry Robert, entomologist at the Office National des Forêts.

\section{Type material}

\section{Holotype}

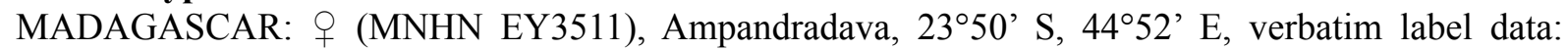
"Madagascar, Bekily [Ampandrandava], reg. sud de l'île, III. 33”, complete.

\section{Paratypes}

MADAGASCAR: 11 우 (EY3512-3522), 6 ฮิ §ิ (EY3523-3528), Bekily, Feb. 1932, Jan.-Mar., May and Dec. 1933; 2 우 (CAS), 2 qq (BNHM, MRAC), 3 ठิ $\widehat{0}$ (AMNH, ISAM, NMKB), same locality, same dates.

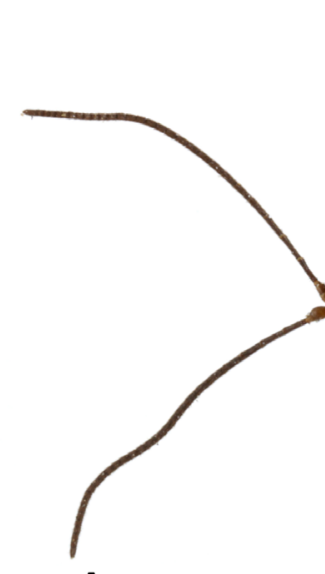

A

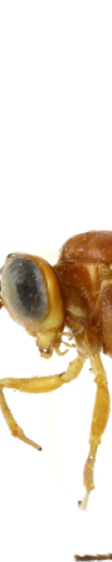

$1 \mathrm{~mm}$
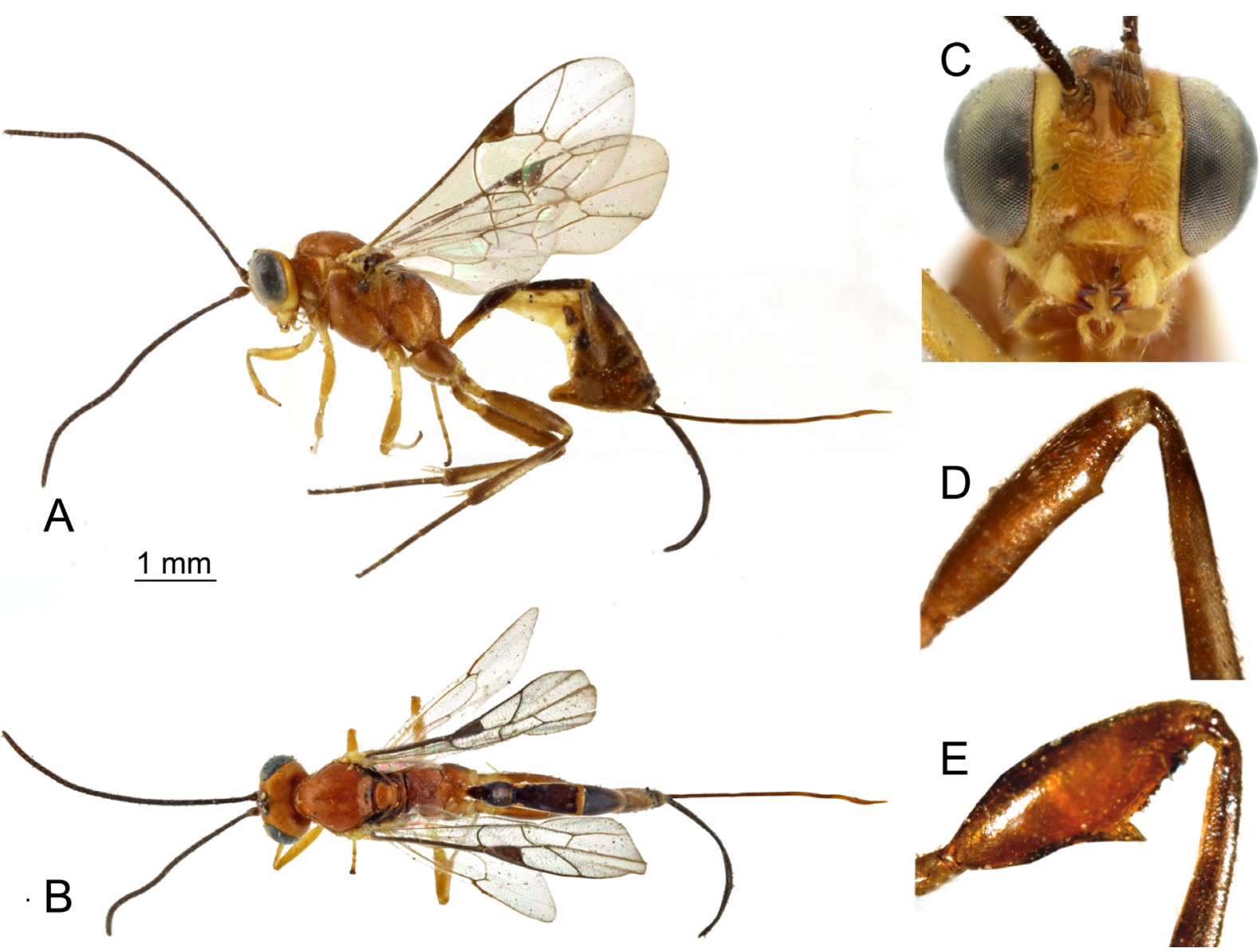

Fig. 14. Pristomerus roberti sp. nov. A. + , habitus, profile. B. + , habitus, dorsal. C. $\odot$, head, facial. D. , , hind femur, profile. E. $\widehat{\jmath}$, hind femur, profile. 


\section{Description}

\section{Female}

LENGTH. 4.1, 3.8 (3.6-4.3) (10 specimens).

HEAD. Constricted behind eyes. Vertex and temple granulate, frons laterally densely punctate-granulate. Ocellar triangle almost equilateral. Face about as wide as frons, mid-longitudinally bulging, shining and at least latero-medially punctate. Clypeus strongly transverse, smoother, moderately granulate. Mandible stout, malar line short. Antenna with 27-32 flagellomeres.

Mesosoma. Moderately elongate, nearly 2 x longer than high. Pronotum smooth with sparse punctures ventrally. Mesoscutum and all pleurae shining and densely punctate, speculum smooth. Scutellum moderately punctate. Propodeum with carination thick, densely punctate-granulate, area basalis opposite, area superomedia about $2 \mathrm{x}$ longer than wide. Legs: hind femur with a small tooth.

Metasoma. Post-petiole, tergite 2 and base of tergite 3 finely aciculate, the following alutaceous with rare punctures. Thyridia elongate. Ovipositor long, its apical third slightly sinuate.

Color. Testaceous-orange. Mandible, clypeus, inner and outer orbits and sometimes face paler. Antenna fuscous. Post-petiole and tergites 2-3 dark brown. Tergite 1 and 2 with yellow hind margin. Tergite 3 paler at apex. Thyridiae yellow. Hind leg infuscate with apex of femur and dorsal margin of tibia paler. Wings hyaline, pterostigma dark brown.

\section{Male}

Length: 3.9 (3.7-4.1) (4 specimens). Mesonotum almost smooth. Face ventrally widened and distinctly larger than frons. Posterior ocelli close to eyes $(\mathrm{OOL}=0.2)$, inter-ocellar distance greater $(\mathrm{POL}=0.6)$. Hind femur swollen, femoral tooth stout and sharp followed by a row of small denticles. Metasoma darker than in female. Hind coxa and femur orange, hind tibia and tarsus brown. Otherwise similar to female.

\section{Distribution}

Madagascar (Toliara province).

Pristomerus vahaza sp. nov. urn:1sid:zoobank.org:act:46D3D30A-E9A1-466A-8082-814DB367F604

Fig. 15

\section{Diagnosis}

Moderately large species; face ivory white; head white and black, remainder of body orange with tergites 1-3 infuscate; face finely and sparsely punctate; clypeus slightly transverse, smooth; mesoscutum moderately punctate-granulate, scutellum sparsely punctate; area superomedia about $3 \mathrm{x}$ longer than wide; female femoral tooth absent or appearing as a weak angulation; ovipositor moderately short, apically sinuate; POL 0.5 ; OOL 1.0; CT 1.4; ML 0.5; OT 1.3-1.4; FFT 0.

\section{Differential diagnosis}

Species superficially close to $P$. caris and related species with white face. Pristomerus vahaza sp. nov. may be distinguished by the combination of an elongate mesosoma, a brown pterostigma and a relatively short ovipositor. The lateral ocellus in male is distinctly more distant from eye margins $(\mathrm{OOL}=0.6)$ than in $P$. hansoni sp. nov. and $P$. caris $(\mathrm{OOL}=0.2)$. 


\section{Etymology}

Refers to the white face: "vahaza" is the Malagasy word for pale foreigners.

\section{Type material}

\section{Holotype}

MADAGASCAR: $q$ (MNHN EY3534), Rogez, 48¹8' S, 48³2’ E, verbatim label data: “Madagascar, Rogez, forêt côte est, II.31", complete.

\section{Paratypes}

MADAGASCAR: 4 우, 7 § Mar., May, Oct. and Dec. 1932; 2 (CAS), same locality.

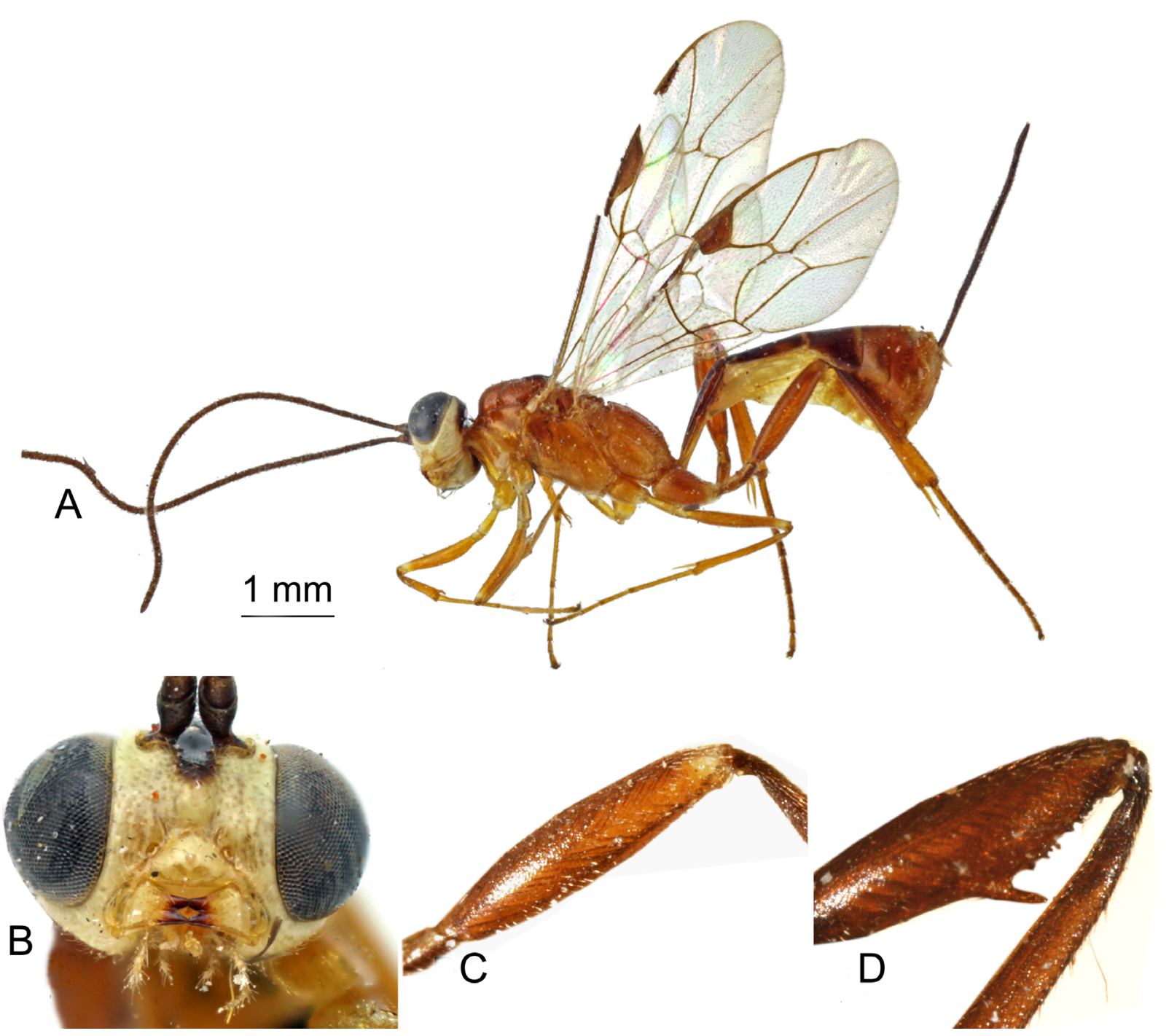

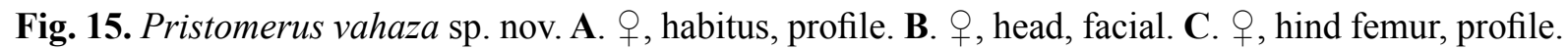
D. $\widehat{O}$, hind femur, profile. 
Other material examined

MADAGASCAR: 1 ภ (MNHN), Manongarivo (1150 m), Dec. 1960 (P. Griveaud Coll.); 1 ㅇ (MNHN), Massif du Tsaratanana, southern slope (2030 m), Andohanambatoafo, 16-18 Dec. 1966 (P. Viette coll.).

\section{Description}

\section{Female}

LENGTH. 5.1, 4.9 (4.7-5.5) (5 specimens).

HEAD. Temple short, head distinctly constricted behind eyes. Vertex finely granulate. Ocellar triangle almost equilateral. Face slightly widened ventrally. Face and frons shining, sparsely and finely punctate. Clypeus smooth, slightly transverse. Malar line short. Mandible short. Antenna with 33 flagellomeres.

Mesosoma. Elongate, about $2.2 \mathrm{x}$ longer than high. Pronotum smooth. Mesoscutum moderately punctate-granulate. Pleurae shining, rather densely punctate-granulate ventrally. Speculum smooth. Scuto-scutellar groove smooth. Scutellum flat, shining, with sparse punctures. Propodeum long, area basalis opposite or petiolate, area superomedia nearly 3 x longer than wide. Wings: hind wing with vein $1 / \mathrm{Cu}+\mathrm{cu}-\mathrm{a}$ almost vertical. Legs: hind femur slender, tooth absent or appearing at most as a weak protuberance.

Metasoma. Post-petiole and tergite 2 finely aciculate, the following alutaceous. Thyridia short and oval. Ovipositor relatively short, apically sinuate.

CoLor. Orange. Head ivory white with antennae, center of frons, vertex and occiput black. A pair of black spots across outer orbits dorsally. Face with a small median brown spot below toruli. Tergites 1-3 infuscate. Ovipositor sheath black. Wings hyaline, pterostigma testaceous.

\section{Male}

Length: 5.0 (4.0-5.5) (7 specimens). Face more widened ventrally and distinctly larger than frons. Interocellar and oculo-ocellar distances equal $(\mathrm{OOL}=\mathrm{POL}=0.6)$. Hind femur swollen with a pointed tooth followed by a row of small denticles. Antennae with 31-33 flagellomeres. Otherwise similar to female.

\section{Distribution records}

Madagascar (Toamasina province).

Pristomerus veloma sp. nov. urn:1sid:zoobank.org:act:C0D38F99-99B0-43A6-8E24-AE23BED6CDF8

Fig. 16

\section{Diagnosis}

Large species; face rufo-testaceous; head and mesosoma rufo-testaceous, metasoma black; face densely punctate-granulate, clypeus smooth and transverse; mesoscutum densely punctate-granulate anteriorly, smoother posteriorly, scutellum punctate; area superomedia about $2 \times$ longer than wide; female femoral tooth strong; ovipositor moderately long, apically sinuate; POL 0.7; OOL 0.7; CT 2.0; ML 0.5; OT $1.5-1.7$; FFT 2.

\section{Differential diagnosis}

Species characterized by the unusual color pattern and the strong femoral tooth of female. 


\section{Etymology}

"veloma" is the Malagasy word for "good-bye, farewell".

\section{Type material}

\section{Holotype}

MADAGASCAR: $q$ (MNHN EY3545), Rogez, 48¹8' S, 48³2’ E, verbatim label data: “Madagascar, Rogez, forêt côte est, XII. 30", complete.

\section{Paratypes}

MADAGASCAR: 2 우, $2 \hat{\jmath}$ (MNHN EY3546-3549), same locality, same date; $1 \hat{\jmath}$ (EY8719), same locality, 1935.

\section{Other material examined}

SOUTH AFRICA: 2 우, 1 § , Goshen, Eastern Cape, Mar. 1954, SAM-HYM P001202.

\section{Description}

\section{Female}

LENGTH. 7.5, 7.2 (7.1-7.5) (3 specimens).

HEAD. Distinctly constricted behind eyes, temple very short, not rounded. Vertex punctate-granulate. Frons mid-longitudinally bulging below central ocellus. Face slightly shorter than frons and slightly widened ventrally, mid-longitudinally distinctly bulging, densely punctate-granulate. Clypeus smooth and transverse. Mandible stout and hairy. Malar line short. Antenna thin with 34-37 flagellomeres.

Mesosoma. Stout, about $1.5 \mathrm{x}$ longer than high. Pronotum centrally smooth, epomia strong. Mesoscutum shining and densely punctate-granulate anteriorly, smoother posteriorly. Scuto-scutellar groove striate,
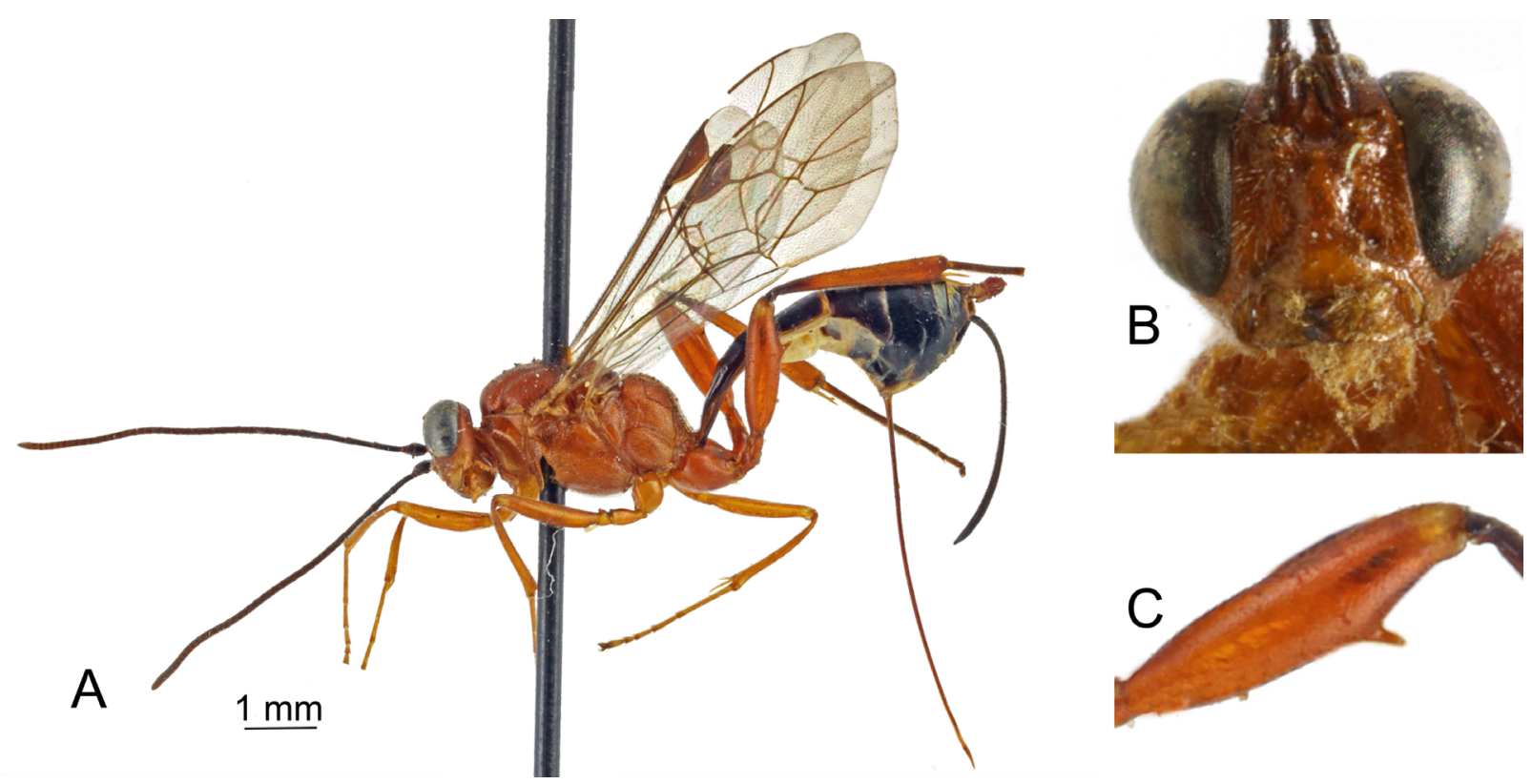

Fig. 16. Pristomerus veloma sp. nov. A. + , habitus, profile. B. $\uparrow$, head, facial. C. $\odot$, hind femur, profile. 
scutellum punctate. Pleurae and propodeum shining and densely punctate, speculum ventrally smooth. Propodeum with strong carination, area basalis truncate, area superomedia about $2 \mathrm{x}$ longer than wide. Legs: femoral tooth fine and acute followed by a raw of very short denticles, denticles sometimes almost indistinct, their bases more or less merging.

Metasoma. Post-petiole, tergite 2 and base of tergite 3 finely aciculate, the following tergites granulate. Tergite 2 about half as long as tergite 1 and about $1.5 \mathrm{x}$ longer than apically wide. Thyridia transverse and oval. Ovipositor thin and moderately long, its apex slightly sinuate.

Color. Head, thorax and legs rufo-testaceous. Antenna, inter-ocellar area, whole metasoma and ovipositor sheath black. Base of hind tibia and hind tarsus infuscate. Tergite 2 usually with a thin yellow margin. Wings hyaline, pterostigma dark brown.

\section{Male}

Length: 6.5 (5.9-7.2) (3 specimens). Ocelli greater, closer to eyes $(\mathrm{OOL}=0.3)$ than from each other $(\mathrm{POL}=0.4)$. Mesonotum smoother with sparse punctures. Thyridia circular. Tooth on hind femur sharper, followed by a more or less merging dense row of fine denticles. Otherwise similar to female.

\section{Distribution}

Madagascar (Toamasina province), South Africa (Eastern Cape).

\section{Remarks}

The three specimens from South Africa have the head differently colored, with face blackish, and mandible and orbits yellow. Furthermore, the dorsal edge of clypeus is densely punctate. They are otherwise strictly similar to the holotype and are included as non-type specimens.

Pristomerus yago sp. nov.

urn:1sid:zoobank.org:act:246E143E-A6B2-46ED-9CBD-9BA6AE654D84

Fig. 17

\section{Diagnosis}

Moderately large species; face rufo-testaceous; general coloration rufo-testaceous, tergites 1-2 dark brown; head strongly constricted behind eyes; face transverse and moderately punctate, clypeus slightly transverse and sparsely punctate; mesoscutum alutaceous with sparse punctures, scutellum smooth; area superomedia about $2 \mathrm{x}$ longer than wide, smooth; female femoral tooth strong; ovipositor moderately long, apically sinuate; POL 0.8; OOL 1.0; CT 1.6; ML 0.5; OT 1.5-1.7; FFT 2.

\section{Differential diagnosis}

Species characterized by the weakly sculptured mesosoma with smooth area superomedia and the strong femoral tooth of female. The male coloration is similar to that of $P$. veloma which is bigger and has a punctate-granulate mesosoma.

\section{Etymology}

Euphonic arrangement of letters.

\section{Type material}

\section{Holotype}

MADAGASCAR: + (MNHN EY3753), Rogez, 48¹8’ S, 48³2’ E, verbatim label data: “Madagascar, Rogez, forêt côte est, II.31", complete. 


\section{Paratypes}

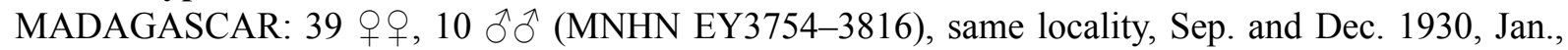
Feb. and Apr. 1931; 1 ㅇ (MNHN EY3817), Andreba, Nov. 1933; 1 ㅇ (MNHN EY3818), Ranomafana,

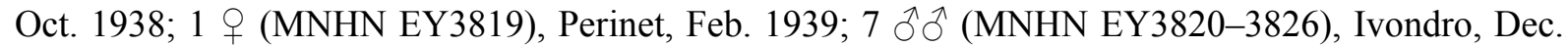

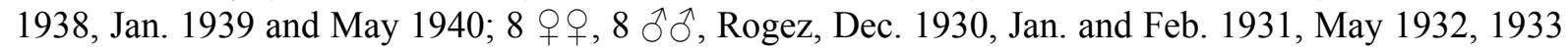
and 1936 (one couple to each of the above mentioned institutions).

\section{Other material examined}


1936; 3 ठै ${ }^{\Uparrow}$ (MNHN), Ivondro, Dec. 1938 and Jan. 1939.

\section{Description}

\section{Female}

Length. 4.8, 4.3 (4.0-4.8) (10 specimens).

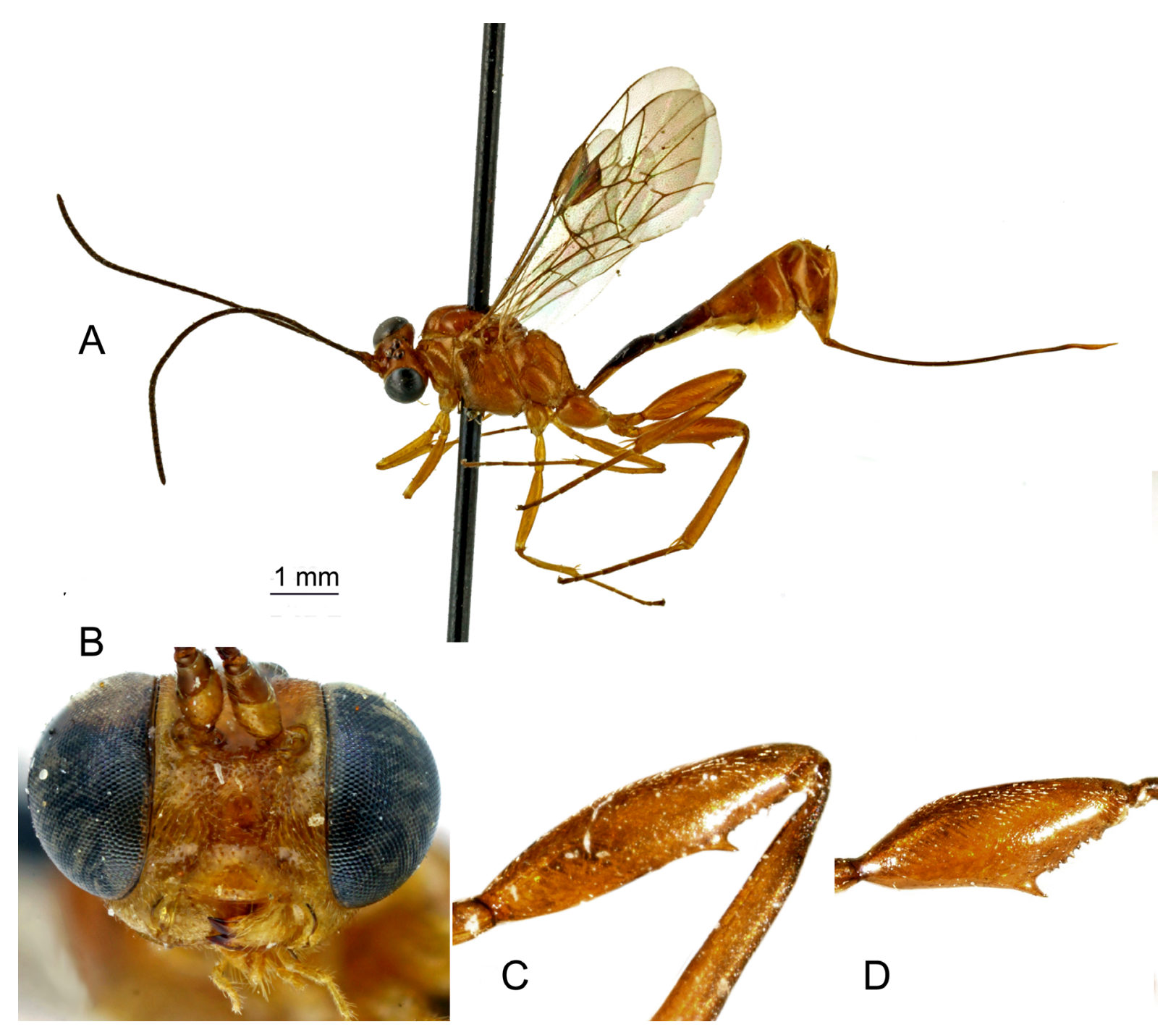

Fig. 17. Pristomerus yago sp. nov. A. $q$, habitus, profile. B. $q$, head, facial. C. + , hind femur, profile. D. $\stackrel{\partial}{ }$, hind femur, profile. 
HeAD. Temple very short, head strongly constricted behind eyes. Vertex granulate. Ocellar triangle equilateral. Face transverse, $1.5 \mathrm{x}$ wider than high and slightly widened ventrally, shining and moderately punctate. Clypeus moderately transverse, weakly convex, shining with sparse puncture. Mandible stout. Malar line short. Antenna with 32-34 flagellomeres.

Mesosoma. Slightly elongate, about $1.7 \mathrm{x}$ longer than high. Mesoscutum finely granulate with sparse punctures, posteriorly smoother. Scuto-scutellar groove striate, scutellum smooth. Mesopleuron shining and sparsely punctate, metapleuron moderately punctate-granulate. Propodeum with strong carination, area basalis opposite or slightly petiolate, area superomedia almost smooth, $2 \mathrm{x}$ as long as wide, area petiolaris with transverse wrinkles. Hind femur slightly swollen, with an acute tooth followed by a series of very small denticles.

Metasoma. Post-petiole, tergite 2 and base of tergite 3 finely aciculate, the following tergites alutaceous. Tergite 2 about $2 \times$ longer than wide. Thyridia shortly oval. Ovipositor moderately long, its apical $1 / 3$ sinuate.

CoLor. Rufo-testaceous. Flagellum, ovipositor sheath and tergites 1-2 dark brown (except the apical margin of tergite 2). Wings hyaline, pterostigma large, dark brown.

\section{Male}

Length: 5.1 (4.8-5.5) (10 specimens). Eyes strongly convergent dorsally. Posterior ocelli widely separated $(\mathrm{POL}=1)$ and very close to eyes $(\mathrm{OOL}=0.2)$. Hind femur strongly swollen with a sharp tooth followed by a dense row of more or less merging fine denticles. Thyridia slightly elongate, oval. Metasoma entirely dark brown. Base of hind tibia darker. Otherwise similar to female.

\section{Distribution}

Madagascar (Toamasina province).

\section{Discussion}

The newly described Pristomerus fauna in Madagascar could be compared to a large body of undetermined material housed at ISAM. This latter material contains hundreds of individuals, collected throughout Sub-Saharan Africa since the beginning of the last century (especially over the last 20 years) and until now Pristomerus has not been identified to species level. This examination led to the description of numerous new species (see also Rousse \& van Noort, in prep.) and also enabled us to get a first assessment of the relationships of the Pristomerus fauna between Madagascar and mainland Africa.

Firstly, we did not find any white-faced species outside of Madagascar, where this color pattern appears to be rather common. Five closely related species (P. caris sp. nov., P. guinness sp. nov., $P$. hansoni $\mathrm{sp}$. nov., $P$. ranomafana sp. nov. and $P$. vahaza sp. nov.) thus share a habitus restricted to the island, most likely representing a local diversification. This is further supported by the large internal variation noticed in the probable $P$. caris species-complex.

Secondly, only three of the 15 species are found outside of Madagascar, namely P. cunctator, P. albescens and $P$. veloma sp. nov., which are also present on the Eastern African coast. No relation could be found with the known Indian fauna. This suggests both an African origin and a high endemism rate for the Malagasy fauna. Such results are far from unexpected, agreeing with the usual endemism rates reported there (Goodman \& Benstead 2003) and in previous analyses of the Malagasy ichneumonid fauna (Seyrig 1932; Heinrich 1938). The genus Enicospilus (Ophioninae) is also very diverse in Afrotropics: Gauld \& Michell (1978) reported 84 species in Madagascar, of which 39 occur on mainland Africa as well. In addition, five Enicospilus species are also present in the Oriental Region, particularly on the 
Indian subcontinent (Yu et al. 2012). By comparing Pristomerus spp. with Enicospilus spp., it might be reasonable to assume that the former genus has a higher endemism rate. However, our current knowledge of Pristomerus in Afrotropics is still too limited to enable any definitive comparison.

\section{Acknowledgments}

We are most thankful to Anne Freitag (Musée Cantonnal de Zoologie de Lausanne), Martina Peeters (Institut Royal des Sciences Naturelles de Belgique), Franck Koch (MNHU) and Gavin Broad (BMNH) for loaning type specimens. We also wish to acknowledge Brian Fisher and Bob Zuparko (CAS), and the Madagascar project team for providing fresher material. The Madagascar project was supported in part by the National Science Foundation under Grant No. DEB-0072713 to B.L. Fisher and C.E. Griswold and DEB-0344731 to B.L. Fisher and P.S. Ward, and in part by the Schlinger Foundation. We especially thank Agnièle Touret-Alby (MNHN) for photographing and registering such a large number of specimens, and Terry Reynolds (ISAM) and Gavin Broad for re-reading the manuscript. And many thanks to all participants of the "gimme a name" contest. This work was funded by the Société Entomologique de France, the South African National Research Foundation and the Claude Leon foundation (Germaine Cousin, SABI and Claude Leon postdoctoral fellowship grants, respectively, to P. Rousse).

\section{References}

Curtis J. 1836. British Entomology; Being Illustrations and Descriptions of the Genera of Insects Found in Great Britain and Ireland 13: 588-624.

Fitton M.G., Shaw M.R. \& Gauld I.D. 1988. Pimpline Ichneumon-flies. Handbooks to the Identification of British Insects 7: 1-110.

Gauld I.D. 1991. The Ichneumonidae of Costa Rica, 1. Memoirs of the American Entomological Institute 47: $1-589$.

Gauld I.D. 2000. The Ichneumonidae of Costa Rica, 3. Memoirs of the American Entomological Institute 63: $1-453$.

Gauld I.D. \& Mitchell P.A. 1978. The Taxonomy, Distribution and Host Preferences of African Parasitic Wasps of the Subfamily Ophioninae (Hymenoptera, Ichneumonidae). Commonwealth Institute of Entomology, Slough, UK.

Gauld I.D. \& Wahl D.B. 2002. The Eucerotinae: a Gondwanan origin for a cosmopolitan group of Ichneumonidae? JournalofNaturalHistory36:2229-2248.http://dx.doi.org/10.1080/00222930110096500

Goodman S.M. \& Benstead J.P. 2003. The Natural History of Madagascar. The University of Chicago Press, Chicago, USA.

Heinrich G. 1938. Les Ichneumonides de Madagascar. 3. Ichneumonidae Ichneumoninae. Vol.25. Académie Malgache, Antananarivo, Madagascar.

Myers N., Mittermeier R.A., Mittermeier C.G., da Fonseca G.A.B. \& Kent J. 2000. Biodiversity hotspots for conservation priorities. Nature 403: 853-858. http://dx.doi.org/10.1038/35002501

Polaszek A., Fitton M.G., Bianchi G. \& Huddleston T. 1994. The parasitoids of the African white rice borer, Maliarpha separatella Ragonot (Lepidoptera: Pyralidae). Bulletin of Entomological Research 84: 65-90. http://dx.doi.org/10.1017/S0007485300032247

Rousse P., Villemant C. \& Seyrig A. 2011. Ichneumonid wasps from Madagascar. 5. Ichneumonidae Cremastinae. Zootaxa 3118: 1-30.

Seyrig A. 1932. Les Ichneumonides de Madagascar. 1. Ichneumonidae Pimplinae. Mémoires de l'Académie Malgache 11: 1-183. 
Tosquinet J. 1896. Contributions à la Faune Entomologique de l'Afrique. Ichneumonides. Société Entomologique de Belgique, Bruxelles, Belgium.

Townes H.K. 1971. The genera of Ichneumonidae, part 4. Cremastinae to Diplazontinae. Memoirs of the American Entomological Institute 17: 1-372.

Wahl D.B. \& Sharkey M.J. 1993. Chapter 10. Superfamily Ichneumonoidea. In: Goulet H. \& Huber J.T. (eds) Hymenoptera of the World: an Identification Guide to Families: 359-509. Agriculture Canada, Ottawa, Canada.

Yu D.S., van Achterberg C. \& Horstmann K. 2012. Taxapad 2012. Ichneumonoidea 2011. Database on flash-drive. www.taxapad.com. Ottawa, Ontario, Canada.

Manuscript received: 24 October 2012

Manuscript accepted: 15 March 2013

Published on: 8 July 2013

Topic editor: Koen Martens

Desk editor: Danny Eibye-Jacobsen

Printed versions of all papers are also deposited in the libraries of the institutes that are members of the EJT consortium: Muséum National d'Histoire Naturelle, Paris, France; National Botanic Garden of Belgium, Meise, Belgium; Royal Museum for Central Africa, Tervuren, Belgium; Natural History Museum, London, United Kingdom; Royal Belgian Institute of Natural Sciences, Brussels, Belgium; Natural History Museum of Denmark, Copenhagen, Denmark. 